\title{
A Rational Theory of Tire-Pavement Friction
}

\author{
Robert H. Smith ${ }^{1}$ and Waheed Uddin ${ }^{2}$ \\ ${ }^{1} 8417$ Smugglers Cove Lane, SW Mukilteo, WA 98275, USA \\ ${ }^{2}$ Center for Advanced Infrastructure Technology (CAIT), University of Mississippi, University, MS 38677-1848, USA
}

Correspondence should be addressed to Robert H. Smith; frictionsmith@comcast.net

Received 9 October 2015; Accepted 24 January 2016

Academic Editor: Patrick De Baets

Copyright ( 2016 R. H. Smith and W. Uddin. This is an open access article distributed under the Creative Commons Attribution License, which permits unrestricted use, distribution, and reproduction in any medium, provided the original work is properly cited.

The present study involves field testing of a tire-loading-based theory of pavement traction in place of the traditional coefficient of friction. An associated hypothesis concerns the indicated existence of a fourth rubber force, surface deformation hysteresis, which is theorized to be independent of tire loading during tire sliding.

\section{Background of NCITEC Project, Objective, and Research Tasks}

The US Department of Transportation (DOT) Research and Innovative Technology Administration (RITA) has awarded funding in 2012 to the National Center for Intermodal Transportation for Economic Competitiveness (NCITEC) at the University of Mississippi to conduct research. The general theme of the project is to promote the development of an integrated, economically competitive, efficient, safe, secure, and sustainable national intermodal transportation network by integrating all transportation modes for both freight and passenger mobility.

(1) Background on Pavement-Tire Friction Properties. In keeping with the CAIT-NCITEC 2012-27 project objective of improving transportation safety, this project evaluates a new approach to understanding roadway and airport runway traction by focusing on the friction forces generated when portions of a tire are sliding on asphalt and concrete pavements in both wet and dry conditions. An associated hypothesis concerns the indicated existence of a fourth rubber friction force, surface deformation hysteresis $\left(F_{\mathrm{Hs}}\right)$, which is theorized to be independent of tire loading during such sliding. In 1966, Kummer proposed [1] a unified engineering theory of slidingtire friction to be the sum of tire/pavement adhesion, or $F_{\mathrm{A}}$, macrohysteretic bulk deformation of the tire tread on rough roads, or $F_{\mathrm{Hb}}$, and physical wear of the tire, or $F_{\mathrm{C}}$. This theory will be augmented with the $F_{\mathrm{Hs}}$ term.

Although the introduction of passenger auto antilock brake systems (ABS) with slip-ratio tolerance in the range of approximately 0.10 to 0.30 has considerably reduced braking sliding in these vehicles, frequent tire sliding occurs in braked commercial vehicles. In addition, changes in auto steering (slip) angles during routine turning can develop lateral friction forces. Regarding segments of the tire tread experiencing such sliding, Haney [2] states the following:

At higher slip angles portions of the tire patch are sliding, and you can get less increase in lateral force with an increase in slip angle... After [a] peak..., lateral forces can fall off $30 \%$ within a few degrees of extra slip angle. At these high slip angles most of the contact patch is sliding, producing a lot of heat and wear. (p. 94)

Thus, significant sliding of the tire in the contact patch during vehicle turning is a routine occurrence, and the friction forces developed should be understood as thoroughly as possible.

In addition to this issue, safety aspects of pavement/tire interaction revealed by a tire-loading-based approach as an advantageous replacement to the traditional use of the coefficient of friction $(\mathrm{CoF})$ and skid number $(\mathrm{SN})$ are also considered. The $\mathrm{CoF}$ is not a material property of rubber, and, as is sometimes assumed, it is not always constant under varying tire loads. Quantifying the actual friction forces 
generated in given conditions should assist in determining the adequacy of currently assumed safety factors.

(2) Study Objective. The objectives of this study are (1) to review and discuss measurement of the traditional friction coefficient and a variable-loading-based theory for determining pavement-tire friction characteristics, (2) to conduct a field testing program to validate the variable loadingbased theory, (3) to evaluate the field test results using the loading-based data analysis and compare them with the results of traditional pavement-tire friction parameters, (4) and to propose the use of a sliding friction index (SFI) as a replacement for the use of the coefficient of friction and skid number.

Locked-wheel skid testing is used in field tests to validate the loading-based theory and illustrate use of the associated data analysis approach.

(3) Research Needs. As discussed in the author's book, Analyzing Friction in the Design of Rubber Products and Their Paired Surfaces [3], use of the CoF approach arose during the important studies of metallic machinery in industry. The initial scientific investigation focused on contacting metal surfaces. Presently accepted metallic friction theory developed from research has begun in the 1940s and 1950s. Introductory physics courses in technical institutions utilized the CoF when illustrating practical applications of metallic friction theory. Unfortunately for engineers, however, many such courses did not emphasize that the CoF (defined as $f=F_{\mathrm{T}} / F_{\mathrm{N}}$, where $F_{\mathrm{T}}$ equals total developed friction force and $F_{\mathrm{N}}$ equals the applied vertical load) does not rationally apply to rubber as it is not a material property of elastomers. Similarly, neither does the skid number (SN), which is defined as the $f$ value multiplied by 100 .

\section{(4) Consultant's Tasks. The consultant's tasks included}

(i) developing a field testing plan involving both asphalt and concrete road pavements,

(ii) identifying and recruiting a competent and wellequipped pavement testing organization,

(iii) conducting traction measurements on dry and wet concrete and asphalt pavements,

(iv) interpreting the results as related to the loading-based hypothesis and comparing them with the traditional $\mathrm{CoF}$ and $\mathrm{SN}$ values.

Each test was conducted at standard speed using eight $F_{\mathrm{N}}$ loads $(883,930,984,1034,1084,1132,1188$, and $1242 \mathrm{lb})$. Temperatures of the tested pavements were recorded.

Application of the theoretical considerations in the variable loading-based data analysis and the results of the associated field studies provide transportation asset management professionals and road designers with a greater understanding of the friction mechanisms that develop in the tire/pavement contact patch. A later section will illustrate and discuss limitations of the traditional $f$ and SN terms. Specific guidelines for application of the study's findings and an implementation statement are presented in Section 8.5.

\section{Alternative Theory and Test Technology Applicable to the Research Approach}

By looking at standard skid test results in a manner different from the traditional $\mathrm{CoF}$ approach, an improved understanding of the mechanisms of rubber friction can be revealed. The field testing plan specified use of a tire/pavement friction tester able to produce and control sliding of a full-scale tire needed to illustrate these mechanisms. This sliding requirement has been demonstrated in Smith's 2008 book [3] on Analyzing Friction and a paper [8] coauthored by Smith and Neubert, detailing the tire/pavement loading-based approach. The approach and theory detailed in Analyzing Friction [3] are based on analysis of more than 100 dry and wet rubber friction tests carried out by others on macroscopically smooth and rough surfaces. A large proportion of these tests were conducted by scientists under controlled laboratory conditions, thereby demonstrating data accuracy through repeatability of results. The present research study generated the rubber microhysteretic friction force by use of a standard, full-scale ASTM ribbed tire in locked-wheel testing [4] and so indicates its existence within engineering accuracy.

The 2011 Smith/Neubert paper [8] serves as a summary of that portion of Smith's 2008 book [3] on Analyzing Friction applicable to the present tire/pavement friction investigation, as well as exemplifying a number of techniques that illustrate how to calculate sliding friction forces developed when tires are loaded to $F_{\mathrm{N}}$ values greater than those used in the present testing.

\subsection{Generation of the Rubber Microhysteretic Friction Force in} Locked-Wheel Skid Tests. Generation of the microhysteretic friction force can be exemplified by analysis of previously conducted locked-wheel testing. In 1974, the Transportation Research Board (TRB) published the results [4] of its extensive investigation concerning correlation and calibration of locked-wheel pavement skid testing in wet conditions. Of the approximately 70 figures presented in the TRB report, one concerned the effects of test wheel loading. The report stated that "the direct effect of test wheel load changes on skid resistance is relatively small... This was confirmed in recent tests and Figure A-41 shows the load dependence of skid resistance as computed from seven tests on different pavements, each test being the mean of 10 lockups." Loads of $800 \mathrm{lb}, 1000 \mathrm{lb}$, and $1200 \mathrm{lb}$ were applied.

Figure 1 presents a plot of the TRB Figure A-41 data [4], exemplifying the loading-based approach in which the ordinate axis represents the total measured friction force $\left(F_{\mathrm{T}}\right)$ in lbf, and the abscissa represents the normal load $\left(F_{\mathrm{N}}\right)$ in lb, applied to the tire. The three TRB data points are shown. It may be noted that a straight-line connects these points. When this straight-line is extrapolated to the $F_{\mathrm{T}}$ axis, an intercept value of $150 \mathrm{lbf}$ is indicated.

In addition, it is seen that Figure 1 plot conforms to the elementary algebraic expression $y=m x+b$, where " $y$ " is the ordinate value, " $x$ " is the abscissa value, " $m$ " is the slope of the straight-line, and " $b$ " is a constant component in all $F_{\mathrm{T}}$ values encompassed by the testing range. The " $b$ " value is considered to quantify the magnitude of $F_{\mathrm{Hs}}, 150 \mathrm{lbf}$. 


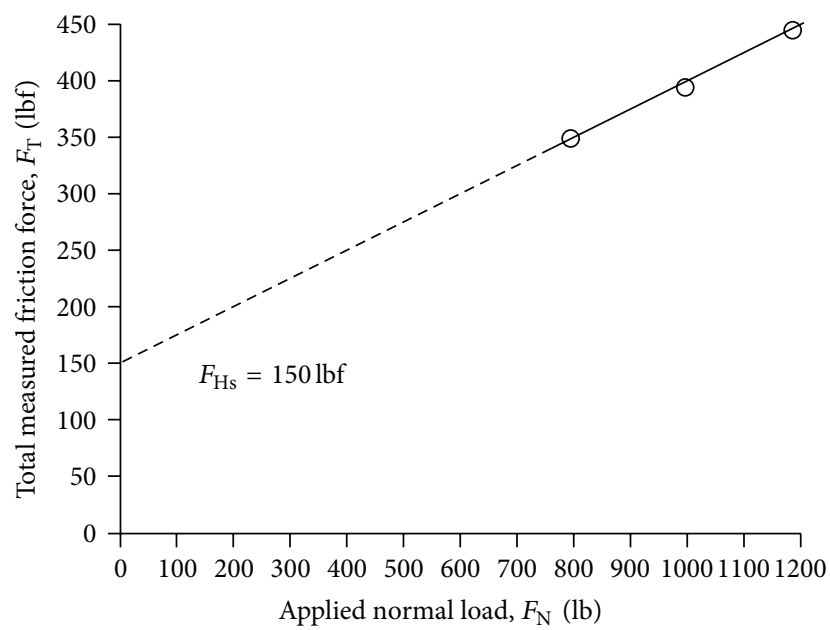

Figure 1: Transportation Research Board [4] Figure A-41 data replotted in accordance with the tire-loading-based approach to sliding-tire-friction-force calculations showing generation of a $150 \mathrm{lbf}$ microhysteretic friction force $\left(F_{\mathrm{Hs}}\right)$ and the direct effect of increasing $F_{\mathrm{T}}$ with increasing $F_{\mathrm{N}}$.

Generation of surface deformation hysteresis is theorized to occur when sliding rubber self-adhesively envelops at least some of the microroughness of a rigid contacted substrate. This microroughness is characterized by the microtexture depth and pavement surface free energy $(\gamma)$. The adhesion mechanism is indicated to arise from the combined surface free energies $(\gamma)$ of the pavement and contacting tire tread. As illustrated in Analyzing Friction [4] and the Smith/Neubert paper [8], if the combined surface free energies $(\gamma)$ are insufficient to produce at least some envelopment of the contacted microroughness, $F_{\mathrm{Hs}}$ does not develop.

Figure 2 illustrates a means for checking the existence and accuracy of the determined $F_{\mathrm{Hs}}$ force: by subtracting the quantified $F_{\mathrm{Hs}}$ value, in this case [4] $150 \mathrm{lbf}$, from the associated $F_{\mathrm{T}}$ values. Plotting the resultants versus the same applied $F_{\mathrm{N}}$ loads as in Figure 1 should yield a straight-line, which extrapolates to the origin, as shown in Figure 2.

\subsection{Scientific Data Support for the Existence of the Rubber} Microhysteretic Friction Force. A mechanism for the production of a microhysteretic rubber friction force (i.e., involving the microtexture of a rigid surface paired with sliding rubber) was theorized by Persson in 1998 [5]. While Persson did not opine that this force would be constant under different applied loads, its characteristics appear to be consistent with those exhibited by the constant $F_{\mathrm{Hs}}$ value, as seen in Figure 1 and shown later in the present testing results.

Persson [5] applied viscoelasticity theory to rubber sliding at a low velocity $(V)$ on a clean, hard, macroscopically rough substrate having a microtexture on its surface of approximately $100 \AA$. Considering the free surface energies $(\gamma)$ of the paired materials, Persson concluded that at room temperature and with a sufficient combined $\gamma$ value, the rubber surface could deform and self-adhesively cover the contacted microroughness with sliding rubber. Persson

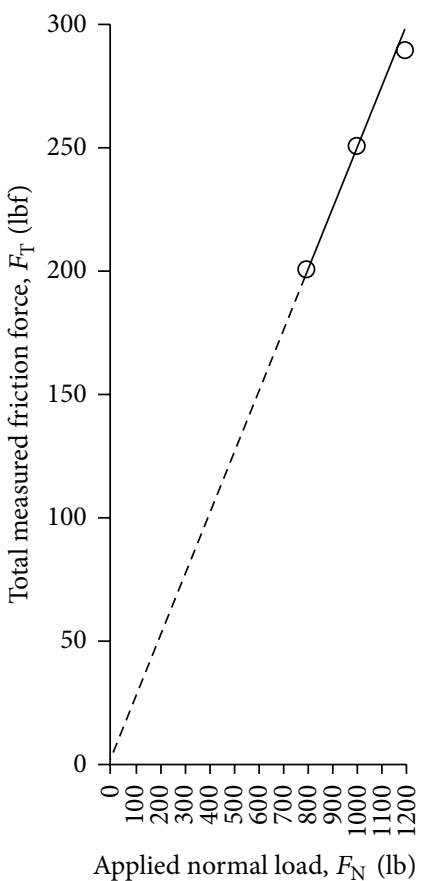

Figure 2: Checking for the existence and accuracy of the $150 \mathrm{lbf}$ microhysteretic friction force, $F_{\mathrm{Hs}}$, by extrapolation of the TRB data points to the origin.

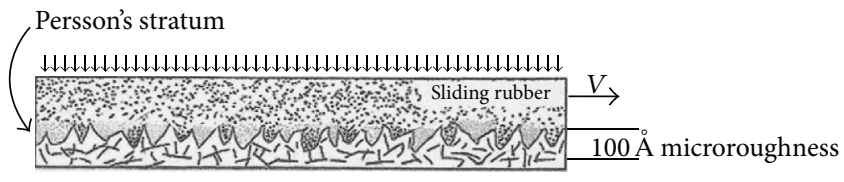

Applied normal load, $F_{\mathrm{N}}$

FIGURE 3: Rubber sliding at velocity $V$ on plate glass having a microroughness of $100 \AA$. The elastomer is compressed into the microstructure and densified by a normal load of $F_{\mathrm{N}}$. Persson's mechanism [5] is also depicted and considered to be a stratum of rubber self-adhering to portions of the glass surface, thereby generating a distinct frictional resistance force.

further calculated that a microroughness approaching $1000 \AA$ could be covered by this mechanism.

Figure 3 depicts rubber sliding at velocity $V$ on plate glass, which typically exhibits a microroughness of about $100 \AA$. The elastomer is compressed into the microtexture and densified by an applied normal load of $F_{\mathrm{N}}$. Persson's mechanism [5] is also at work and considered to be a stratum of rubber self-adhering to portions of the glass surface and thereby generating a distinct frictional resistance force.

Further scientific support for the existence of the $F_{\mathrm{Hs}}$ force is seen in laboratory testing arising from the experience gained during World War II with the use of synthetic rubber tires. It was realized that such tires were more likely to slip on ice than were those made from natural rubber (NR). Pfalzner [6] carried out reproducible laboratory testing in a cold room comparing the sliding frictional resistance of NR to formulations of synthetic Hycar (acrylonitrile butadiene) and GR-S (styrene butadiene). Pfalzner prepared 1 inch $^{2} \times$ 


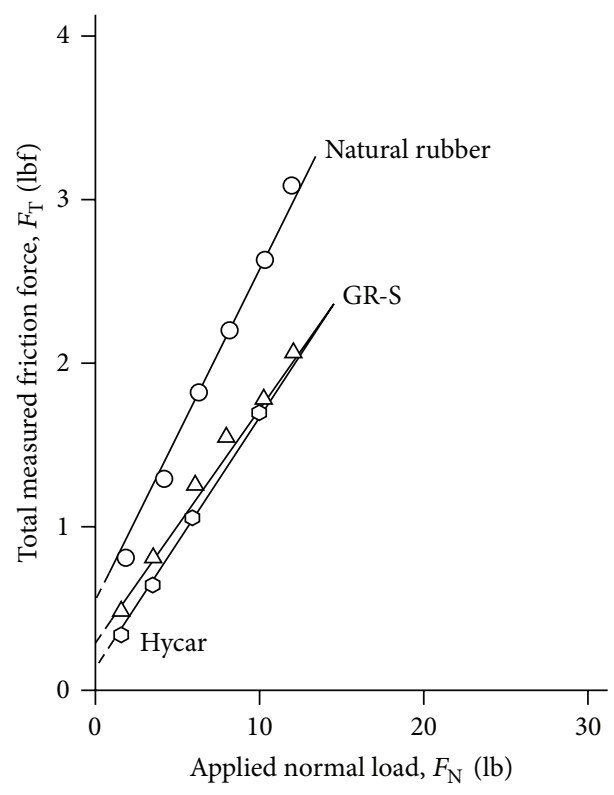

FIgURE 4: Results of Pfalzner's [6] sliding friction testing of natural rubber and synthetic Hycar and GR-S on dry, macroscopically smooth ice showing generation of a microhysteretic friction force in each elastomer (from [3], CRC Press, 2008, with permission).

0.25 inch samples and applied normal loads to them in the range of 42 psi to 100 psi while mounted on an ice-covered, electrically driven turntable rotating at a constant speed of $50 \mathrm{rpm}$. The testing was carried out at $20^{\circ} \mathrm{F}$. Freezing to produce ice was done in such a manner that it was both dry and macroscopically smooth. Figure 4 presents results from Pfalzner's testing [6].

Generation of the microhysteretic friction force in natural rubber, having a magnitude of about $0.6 \mathrm{lbf}$, is evidenced in Figure 4 results from Pfalzner's testing [6]. The GR-S and Hycar plots indicate generation of the $F_{\mathrm{Hs}}$ force having magnitudes of approximately $0.30 \mathrm{lbf}$ and $0.25 \mathrm{lbf}$, respectively. These results are consistent with the tire slipperiness observations made during World War II. In addition to providing an indication of the existence of $F_{\mathrm{Hs}}$, the test results suggest that its slip resistance contribution on ice should not be overlooked.

The 1994 research of Mori et al. [7] also supports the existence of $F_{\mathrm{Hs}}$. Their laboratory-controlled studies focused on clarifying the role of surface free energy $(\gamma)$ on the adhesion forces generated in a sliding configuration when rubber is paired with different, macroscopically smooth surfaces under varying applied load. The vulcanized specimens were formed in specially fabricated molds which possessed different surface free energies, thereby imparting different surface free energies to the surfaces of the rubber specimens. This technique allowed each sample to retain the inherent deformational properties of its bulk material. The various specimens tested included styrene butadiene rubber (SBR), having been molded to possess both high-adhesion and lowadhesion surfaces. The SBR was paired with macroscopically smooth Teflon.

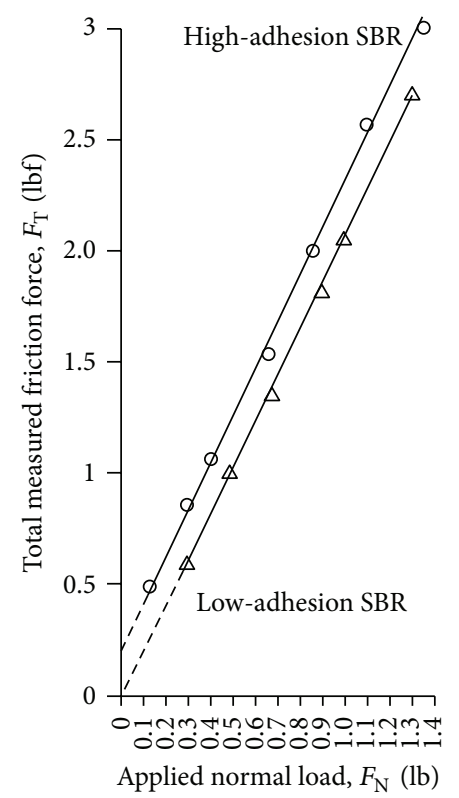

FIGURE 5: Plots of the Mori et al. [7] test results from high-adhesion and low-adhesion SBR sliding on Teflon ${ }^{\circledR}$, indicating generation of the microhysteretic rubber friction force $\left(F_{\mathrm{Hs}}\right)$ and its absence, respectively.

One SBR sample was molded on macroscopically smooth Teflon to yield a low surface free energy material. Another SBR specimen was molded on macroscopically smooth chrome to yield a high surface free energy SBR. Both of these were put in sliding contact with a Teflon surface and a load was applied.

Figure 5 presents the Mori et al. [7] results, plotted in accordance with the loading-based theory to reveal indication of the rubber microhysteretic friction force, if present. It is seen that extrapolation of the high-adhesion (chrome mold) SBR-Teflon pairing plot evidences production of an $F_{\mathrm{Hs}}$ force having a magnitude of approximately $0.2 \mathrm{lbf}$. The lowadhesion SBR-Teflon pairing plot extrapolates to the origin, however, indicating the absence of $F_{\mathrm{Hs}}$.

\section{Reconsideration of the Coefficient of Friction and Skid Number}

3.1. The 1974 TRB Report. The 1974 TRB report [4] stated that "the direct effect of test wheel load changes in skid resistance is relatively small... This was confirmed in recent tests and Figure A-41 (Figure 6) shows the load dependence of skid resistance as computed from seven tests on different pavements, each being the mean of 10 lockups." With reference to Figure 1, however, shows that, opposite to the stated belief, the direct effect of changes in wheel load when the tire is sliding is significant, as illustrated on the $F_{\mathrm{T}}$ axis. The largest $F_{\mathrm{T}}$ force was produced by the largest $F_{\mathrm{N}}$ load. Increases in $F_{\mathrm{N}}$ can increase the real area of tire/pavement contact. Such contact growth can produce greater adhesion [3], a principal tire/pavement friction force. Greater adhesion can also increase tire contact area with 


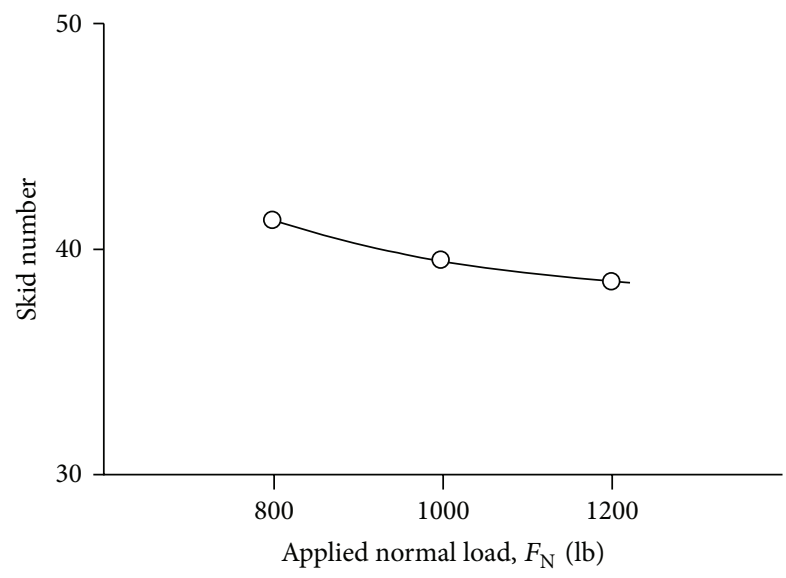

FIgURE 6: Transportation Research Board [4] Figure A-41 data replotted as skid number versus applied normal load $\left(F_{\mathrm{N}}\right)$. As shown in Figure 1, the largest friction force developed, approximately $445 \mathrm{lbf}$, corresponds to the largest applied load, $1200 \mathrm{lb}$, in wet conditions.

pavement macroroughness, adding to macrohysteretic $\left(F_{\mathrm{Hb}}\right)$ friction force development through greater bulk deformation of the tire tread.

Figure 6 expresses SN versus applied normal load. A moderately decreasing hyperbolic curve for the three applied loads of $800 \mathrm{lb}, 1000 \mathrm{lb}$, and $1200 \mathrm{lb}$ is seen, indicating that the frictional resistance decreases with increasing load when the opposite is true. Application of the variable loadingbased approach in sliding friction data analysis can enhance interpretation of skid test results.

3.2. Use of CFMEs to Assess Airport Pavement Traction. Airport pavement traction is also assessed using the CoF. At present it is common practice to use the so-called CFMEs, or Continuous Friction Measuring Equipment, for this purpose [8]. Such equipment is approved by the Federal Aviation Administration (FAA) and can comprise instrumented autos, pickups, or trailers. These smooth-tire tests are conducted at a fixed percent slip, rather than locked-wheel sliding. They are carried out in accordance with an ASTM standard [10]. Because these tests involve slipping, the theorized microhysteretic friction force, $F_{\mathrm{Hs}}$, is not generated. As a consequence, the microhysteretic friction contribution to traction is not determined.

Figure 7 presents the results of such CFME testing carried out in 2009 on an "almost polished," ungrooved, concrete runway taxiway in dry conditions at 17 percent tire slip using a towed trailer incorporating the testing tire in straight-line operation at a velocity of $30 \mathrm{mph}$ at $86^{\circ} \mathrm{F}$ ambient temperature. The CoF data points were obtained by varying the $F_{\mathrm{N}}$ loads applied to the tire. As shown, the plot extrapolates to the origin indicating that the $F_{\mathrm{Hs}}$ force was not generated.

3.3. Examining the Reported START Program Results. Yager et al. [9] reported results obtained in the Surface Traction and Radial Tire (START) Program conducted by the American

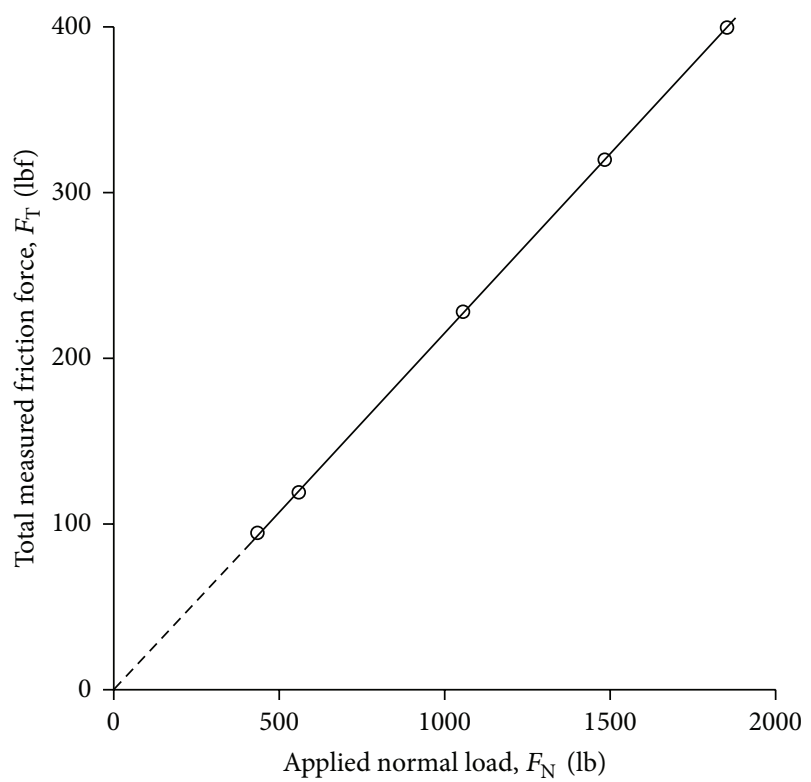

FIGURE 7: Results of CFME testing [8] on an ungrooved concrete runway taxiway at 17 percent tire slip in dry conditions illustrating the inability to generate the microhysteretic friction force (reproduced with permission from the International Journal of Pavements ${ }^{\odot}, 2011$ )

aircraft industry, the National Aeronautics and Space Administration (NASA), and the FAA. The program's particular focus was on the evaluation of tire rolling resistance, braking, and cornering performance in dry conditions on concrete. Three full-size commercial aircraft tire types-radial-belted, bias-ply, and $\mathrm{H}$-type-were investigated.

The studies were carried out at NASA Langley's Aircraft Landing Dynamics Facility, which provided a 2,800-ft long textured concrete test track runway. The runway's macrotexture was measured using the NASA grease sample technique [11] and found to have an average depth of $0.0051 \mathrm{in}$. Cornering performance was assessed by use of a 60 ton tire-carriage operating at a velocity of 100 knots and applying normal loads $\left(F_{\mathrm{N}}\right)$ on freely rotating tires of up to $25,000 \mathrm{lb}$. The carriage was instrumented to measure the total side friction force, $F_{\mathrm{TS}}$, generated at different tire slip angles of interest, and reported values of the side friction coefficient, $F_{\mathrm{TS}} / F_{\mathrm{N}}$.

Figure 8 presents the side coefficient of friction $\left(F_{\mathrm{TS}} / F_{\mathrm{N}}\right)$ results reported [9] by the START Program for the biasply tire tested at five slip angles of interest. It is seen that each plot yields a straight-line having a pronounced downward slope. Conventional interpretation of rubber friction coefficients would conclude that lateral resistance to sliding was decreasing with increasing $F_{\mathrm{N}}$ at all slip angles. As seen in Figure 9, however, in which the same data are plotted in accordance with the loading-based approach (previously explained in Figure 1) to quantify $F_{\mathrm{Hs}}$ values, the side friction force is increasing. This is another example of improved data interpretation for analyzing the coefficient of friction. Table 1 presents the approximate values of the $F_{\mathrm{Hs}}$ force at each tire slip angle. 


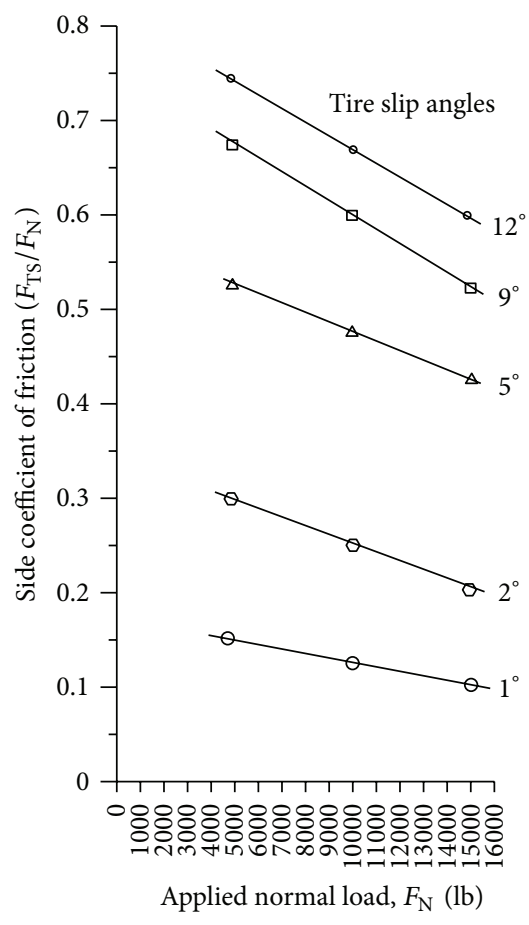

FIGURE 8: Side coefficient of friction results reported by the START [9] Program indicates that lateral frictional resistance to sliding in the tire contact patch decreases with increasing applied load.

TABLE 1: Approximate values of the microhysteretic rubber friction force, $F_{\mathrm{Hs}}$, generated during the Yager et al. [9] sliding, side friction force tests of full-scale, rotating, and bias-ply aircraft tires at five different slip angles.

\begin{tabular}{lcc}
\hline Tire slip angle & $\begin{array}{c}\text { Value of } \\
\text { microhysteretic } \\
\text { force }\end{array}$ & $\begin{array}{c}\text { Side CoF at } \\
10,000 \mathrm{lb} \text { load }\end{array}$ \\
\hline $1^{\circ}$ & $450 \mathrm{lbf}$ & 0.125 \\
$2^{\circ}$ & $900 \mathrm{lbf}$ & 0.25 \\
$5^{\circ}$ & $1,100 \mathrm{lbf}$ & 0.475 \\
$9^{\circ}$ & $1,300 \mathrm{lbf}$ & 0.6 \\
$12^{\circ}$ & $1,600 \mathrm{lbf}$ & 0.675 \\
\hline
\end{tabular}

Figures 8 and 9 side friction test results on an airport-like test track pavement indicate generation of $F_{\mathrm{Hs}}$ forces at all slip angles. These forces are produced due to good pavement microtexture depth and sufficient combined surface free energies of the tire and pavement. The conventional quantification of slip resistance values expressed as side $\mathrm{CoF}$ is shown in Table 1. Its use simply ignores these $F_{\mathrm{Hs}}$ forces arising in the tire contact patch and the presence of a microtexture on the pavement surface.

\section{Methodology and Factors for Field Tests in Current Study}

In the current NCITEC 2012-27 project controlled slidingtire friction testing of asphalt and concrete pavement was

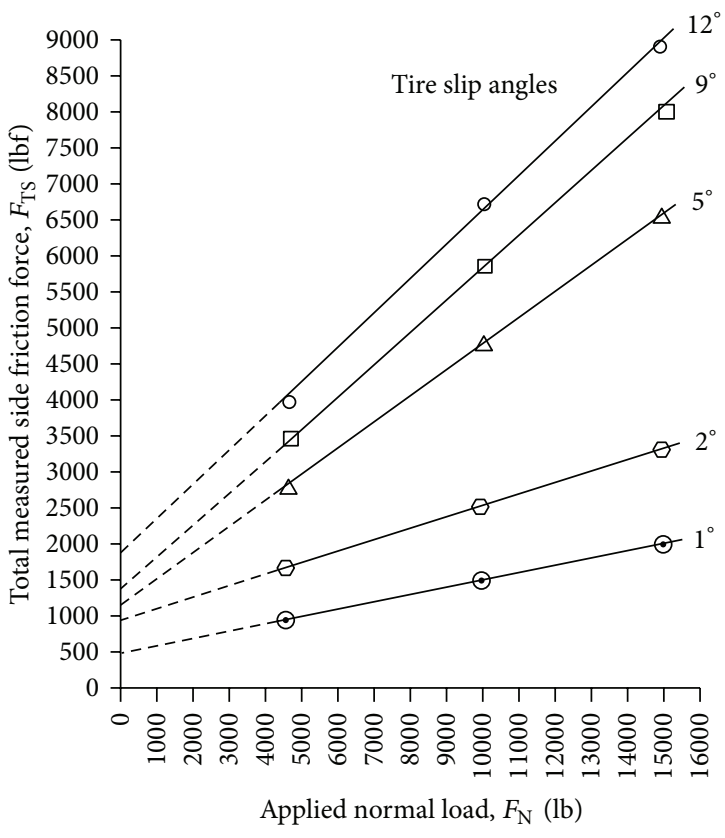

FIGURE 9: Yager et al. [9] side friction force results from tests of full-scale, freely rotating aircraft tires on textured concrete at five different slip angles, replotted in accordance with the tire-loadingbased approach illustrating quantification of the load-dependent side friction force $\left(F_{\mathrm{TS}}\right)$ and values of the associated constant microhysteretic friction force, $F_{\mathrm{Hs}}$, shown in Table 1, obtained by extrapolation to the side friction force axis.

accomplished by using a locked-wheel skid trailer device fitted with a standard, full-scale tire. Instead of the conventional single-load, locked-wheel testing, however, eight different loads were applied to the tire sliding on both asphalt and concrete pavements in wet and dry conditions, as presented in Section 1(4).

4.1. Pavement Friction Testing Equipment and Standards. Tire/pavement friction testing was carried out using an instrumented locked-wheel device provided and operated by International Cybernetics Corporation (ICC) of Largo, Florida. This tester is capable of producing and controlling sliding of a previously conditioned, standard, full-scale ribbed tire (ASTM E501-08) [12] while measuring the total friction force generated. It was operated in accordance with ASTM E274/E274M-11 [13], the current standard for such testing, except that the standard-specified applied load of 1085 $\pm 15 \mathrm{lb}$ was replaced by the loads listed in Section 1(4). The individual, level pavement test sections were of uniform age, material composition, and wear and were free from major defects and obvious surface contamination. ICC has served governmental and consultancy clients since 1975 and has received testing contracts from the United States and around the world. It supplies both hardware and software to meet friction test data-collection and analysis needs.

4.2. Factors and Variables of Test Program. The following two factors were considered for conducting field tests: (1) 
pavement type at two levels (asphalt surfaced and concrete surfaced pavements) and (2) pavement surface condition (dry and wet). Both pavement types were tested using the eight loads listed in Section 1(4). Five lockups were carried out for each load in the dry condition. Five sets of three lockups were carried out for each different tire load in the wet condition. This sampling resulted in four sets of test data collected at each of the eight normal test loads.

In accordance with ASTM E274/E274M-11 [13], the locked-wheel tester slid the test tire at a constant $40 \pm 1 \mathrm{mph}$ velocity. The eight different vertical loads ranging from 883 to $1,242 \mathrm{lb}$ were applied to the tire's centerline under the different test conditions. In accordance with Section 4.7 of this standard concerning pavement wetting [13], the quantity of water applied in the simulated wet tests at $40 \pm 1 \mathrm{mph}$ was $4.0 \mathrm{gal} \pm 10 \% / \mathrm{min} \cdot \mathrm{in}$. of wetted width, amounting to $28 \mathrm{gal} / \mathrm{minute}$.

4.3. Data Collection and Interpretation of Results. Each of four sliding locked-wheel tests generated eight mean values of measured friction force versus applied normal load for the asphalt and concrete pavements in wet and dry conditions. These results have been plotted on conventional rectangular coordinates providing a visual depiction of changes in the magnitude of the developed friction forces as tire loading changes.

The eight different $F_{\mathrm{N}}$ tire loads used in the asphalt and concrete testing were obtained by placing individual steel slab loads in the loading box located at the rear of the test trailer. The load applied to the tire was controlled by the selected weights placed in this box.

\section{Locked-Wheel Testing}

5.1. Dry Asphalt Pavement Testing. Dry testing of asphalt using the ICC tester, always operated by the same experienced engineer, began on Belcher Road in Largo, Florida, on March 18 and was completed on March 22, 2013, during daylight hours. Traffic on Belcher Road was moderate; no significant interference with traffic took place during the testing at 40 $\pm 1 \mathrm{mph}$. Figure 10 depicts the starting point of these tests. Although some clouds were present, no rain fell during the dry asphalt study.

The asphalt pavement was 18 to 20 months old with no significant polishing. Figure 11 depicts a close-up of the Belcher Road pavement on which the skid testing was done. A US quarter placed on the pavement has been included to assist in depicting the lack of polishing.

A new, run-in, full-scale ASTM E501-08 ribbed tire mounted on the left side of the tester with the standard $24 \pm$ 0.5 psi inflation pressure was used. Three preliminary lockups with the same tire loading were done for quality control purposes.

Five lockup cycles of five individual tests were done for each of the eight applied loads. The results were averaged to obtain a mean value for the total measured friction force, $F_{\mathrm{T}}$, generated by each load. These test data were always obtained in the same lateral roadway position in the same operating lane, recorded for $1 \mathrm{sec}$. Figure 12 presents the dry

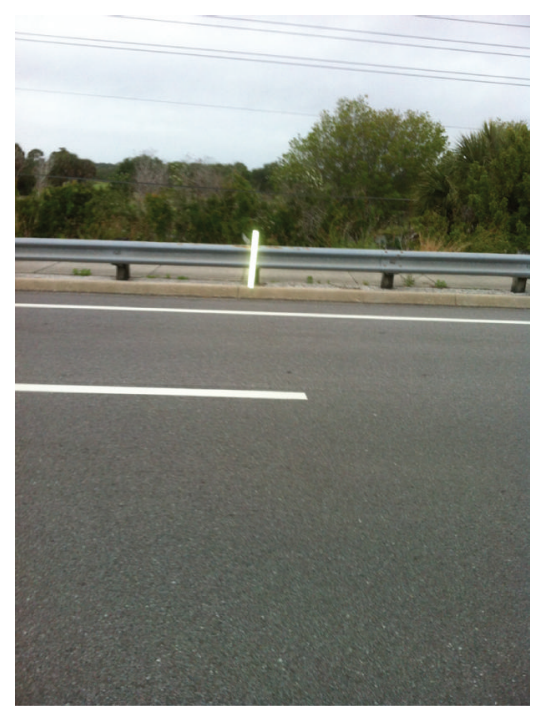

FIgURE 10: Starting point for the Belcher Road asphalt testing in Largo, Florida.

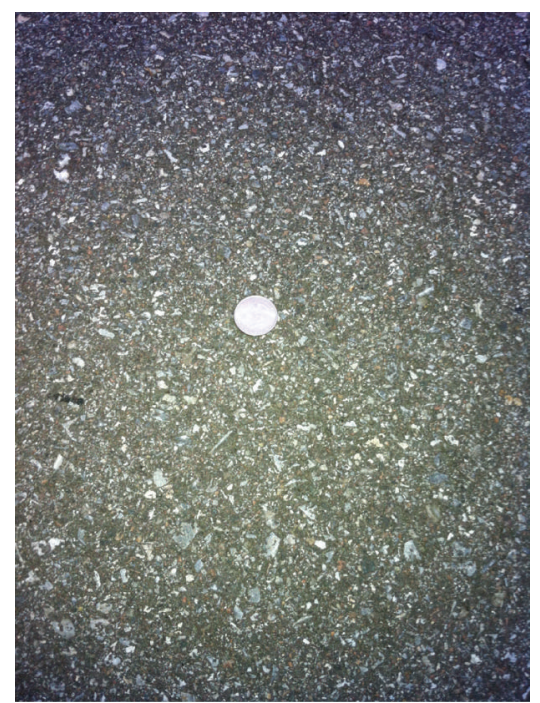

FIGURE 11: Close-up of the Belcher Road asphalt pavement depicting the lack of polishing and presence of microtexture.

Belcher Road results plotted in accordance with loadingbased approach. When compared to the CoF versus load plot seen in Figure 6, the test data plots provide superior insight into the friction-generating mechanisms active in the tire/pavement contact patch. Table 2 presents the normal loads and their associated $F_{\mathrm{T}}$ friction-force values.

It is seen that six of the eight $F_{\mathrm{T}}$ values, when connected by a straight-line and extrapolated to the $y$-axis, indicate generation of the microhysteretic friction force, $F_{\mathrm{Hs}}$, having a magnitude of about $140 \mathrm{lbf}$. The plotted points for two of the applied loads, $984 \mathrm{lb}$ and $1034 \mathrm{lb}$, however, are considered outliers. These may be associated with puffs of white smoke which emanated from the tire/pavement contact patch during all dry lockups. 
TABLE 2: Individual weights selected for use in controlling the dynamic load $\left(F_{\mathrm{N}}\right)$ applied to test tire during lockups and measured $F_{\mathrm{T}}$ values dry asphalt pavement testing.

\begin{tabular}{cccc}
\hline$\#$ & $F_{\mathrm{N}}$ normal load & Increase in load, \% & $F_{\mathrm{T}} \mathrm{lbf}$ \\
\hline 1 & $883 \mathrm{lb}$ & - & 693 \\
2 & $930 \mathrm{lb}$ & 5.3 & 705 \\
3 & $984 \mathrm{lb}$ & 11.4 & 650 \\
4 & $1034 \mathrm{lb}$ & 17.1 & 597 \\
5 & $1084 \mathrm{lb}$ & 22.8 & 850 \\
6 & $1132 \mathrm{lb}$ & 28.2 & 879 \\
7 & $1188 \mathrm{lb}$ & 34.5 & 890 \\
8 & $1242 \mathrm{lb}$ & 40.7 & 923 \\
\hline
\end{tabular}

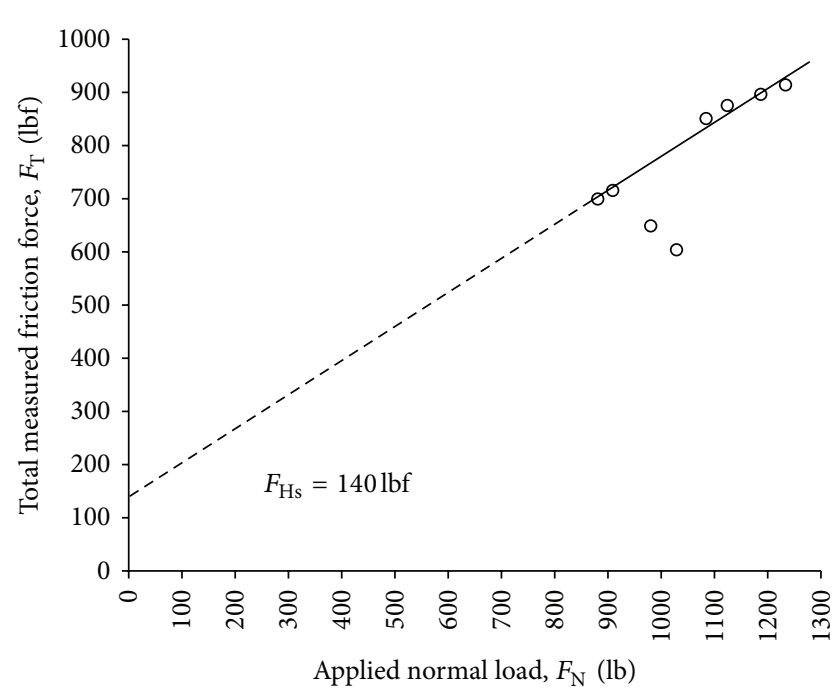

FIGURE 12: Dry Belcher Road test results.

Examination of the pavement at the dry lockup locations revealed that soft spots had developed on the tire, as indicated by black streaks of rubber on the pavement surface. Smoke production may have resulted from the presence of the mechanism which is common in tires during aircraft landings. Heat degradation of the tires and rubber vaporization can cause white smoke to be generated. A professional commercial pilot has stated [14] that "the smoke is the result of a wheel which is not turning in flight making contact with a stationary runway. The wheel must accelerate to the landing speed very quickly. During that acceleration, there is a short time when the tire is skidding, which produces the smoke."

While tire softening occurred during all dry lockups as a result of friction, the $984 \mathrm{lb}$ and $1034 \mathrm{lb}$ load testing of Belcher Road was also subjected to the highest continuous pavement temperatures arising from solar radiation, potentially resulting in additional tire softening with consequent reduction in the generated friction force. The pavement temperature during these two test cycles was $119^{\circ} \mathrm{F}$. Pavement temperatures during application of the other six applied loads averaged a continuous $82^{\circ} \mathrm{F}$.
TABLE 3: Individual weights selected for use in controlling the dynamic load $\left(F_{\mathrm{N}}\right)$ applied to test tire during lockups and measured $F_{\mathrm{T}}$ values wet asphalt pavement testing.

\begin{tabular}{cccc}
\hline$\#$ & $F_{\mathrm{N}}$ normal load & Increase in load, \% & $F_{\mathrm{T}} \mathrm{lbf}$ \\
\hline 1 & $883 \mathrm{lb}$ & - & 395 \\
2 & $930 \mathrm{lb}$ & 5.3 & 384 \\
3 & $984 \mathrm{lb}$ & 11.4 & 402 \\
4 & $1034 \mathrm{lb}$ & 17.1 & 455 \\
5 & $1084 \mathrm{lb}$ & 22.8 & 449 \\
6 & $1132 \mathrm{lb}$ & 28.2 & 452 \\
7 & $1188 \mathrm{lb}$ & 34.5 & 431 \\
8 & $1242 \mathrm{lb}$ & 40.7 & 449 \\
\hline
\end{tabular}

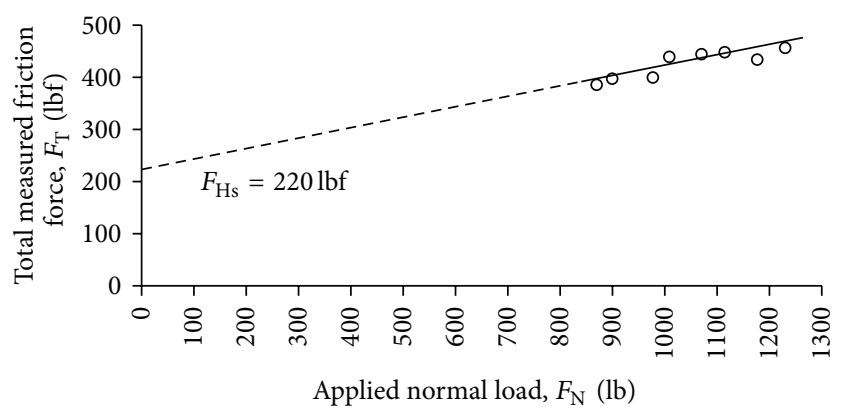

FIgURE 13: Wet Belcher Road test results.

5.2. Wet Asphalt Pavement Testing. Wet testing of the same asphalt pavement using the ICC tester, always operated by the same experienced engineer, began on Belcher Road in Largo, Florida, on March 18, 2013, and was completed on March 22, 2013, both during daylight hours. Traffic on Belcher Road was moderate; no significant traffic interference took place with the testing at $40 \pm 1 \mathrm{mph}$.

A loading-based plot of the resulting test data is presented in Figure 13. Generation of an $F_{\mathrm{Hs}}$ friction force of about $220 \mathrm{lbf}$ is indicated. Table 3 presents the individual $F_{\mathrm{N}}$ weights utilized and the resulting associated $F_{\mathrm{T}}$ values produced.

The new, run-in, full-scale ASTM E501-08 ribbed tire mounted on the left side of the tester with the standard 24 \pm 0.5 psi inflation pressure [4] was used.

Five lockup cycles of three individual tests were done for each of the eight applied loads. The results were averaged to obtain a mean value for the total measured friction force, $F_{\mathrm{T}}$, generated by each load. These test data were always obtained in the same lateral roadway position in the same operating lane, recorded for $1 \mathrm{sec}$.

It is seen that seven of the $F_{\mathrm{T}}$ values fall on or very near to a straight-line which, when extrapolated, indicates generation of the microhysteretic friction force, $F_{\mathrm{Hs}}$, having a magnitude of about $220 \mathrm{lbf}$. The $1,188 \mathrm{lb}$ data point, however, which is slightly below the straight-line, could be considered an outlier. Drawing on the experience of ICC from their routine locked-wheel testing in wet conditions likely revealed the apparent discrepancy. The friction data for the $1,188 \mathrm{lb}$ and $1,242 \mathrm{lb}$ loads were collected three days after the friction 


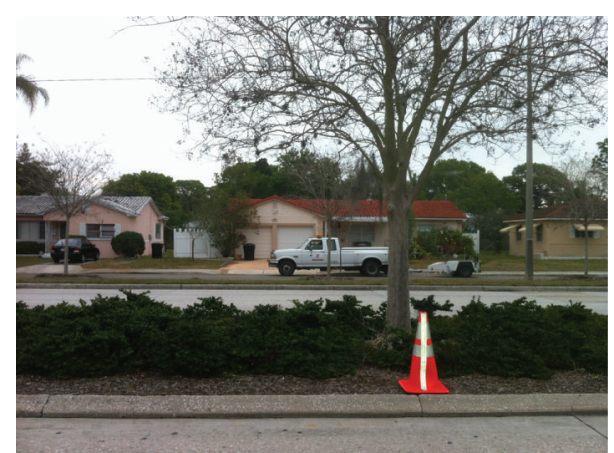

FIgURE 14: Starting point for the Tyrone Boulevard testing in St. Petersburg, Florida.

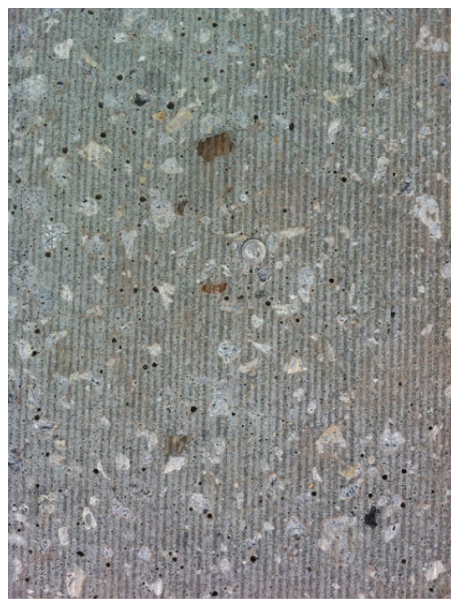

FIgURE 15: Close-up of the polished Tyrone Boulevard pavement showing the longitudinal tining.

data for the other loads. It had been noticed that friction data obtained on different days could show such different results, probably associated with pavement temperature variations during such periods.

5.3. Dry Concrete Pavement Testing. Dry testing of concrete pavement using the ICC tester, always operated by the same experienced engineer, began on Tyrone Boulevard in St. Petersburg, Florida, on March 18, 2013, and was completed on March 22, 2013, both during daylight hours. Traffic on Tyrone Boulevard was moderate; no significant interaction took place between it and tester as $40 \pm 1 \mathrm{mph}$. Figure 14 depicts the starting point of these tests, as well as the ICC truck and trailer. Although some clouds were present, no rain was experienced during the dry concrete study.

Figure 15 presents a close-up of the polished Tyrone Boulevard pavement. A US dime has been placed on the pavement to assist in depicting the surface condition and its treatment. The Florida Department of Transportation requires that all concrete roads undergo tining, a process in which metal prongs are dragged on semihardened concrete to create grooves transversely or longitudinally [15]. The longitudinal grooves in the otherwise polished Tyrone Boulevard
TABLE 4: Individual weights selected for use in controlling the dynamic load $\left(F_{\mathrm{N}}\right)$ applied to test tire during lockups and measured $F_{\mathrm{T}}$ values dry concrete pavement testing.

\begin{tabular}{cccc}
\hline$\#$ & $F_{\mathrm{N}}$ normal load & Increase in load, $\%$ & $F_{\mathrm{T}} \mathrm{lbf}$ \\
\hline 1 & $883 \mathrm{lb}$ & - & 666 \\
2 & $930 \mathrm{lb}$ & 5.3 & 743 \\
3 & $984 \mathrm{lb}$ & 11.4 & 786 \\
4 & $1034 \mathrm{lb}$ & 17.1 & 824 \\
5 & $1084 \mathrm{lb}$ & 22.8 & 848 \\
6 & $1132 \mathrm{lb}$ & 28.2 & 878 \\
7 & $1188 \mathrm{lb}$ & 34.5 & 903 \\
8 & $1242 \mathrm{lb}$ & 40.7 & 931 \\
\hline
\end{tabular}

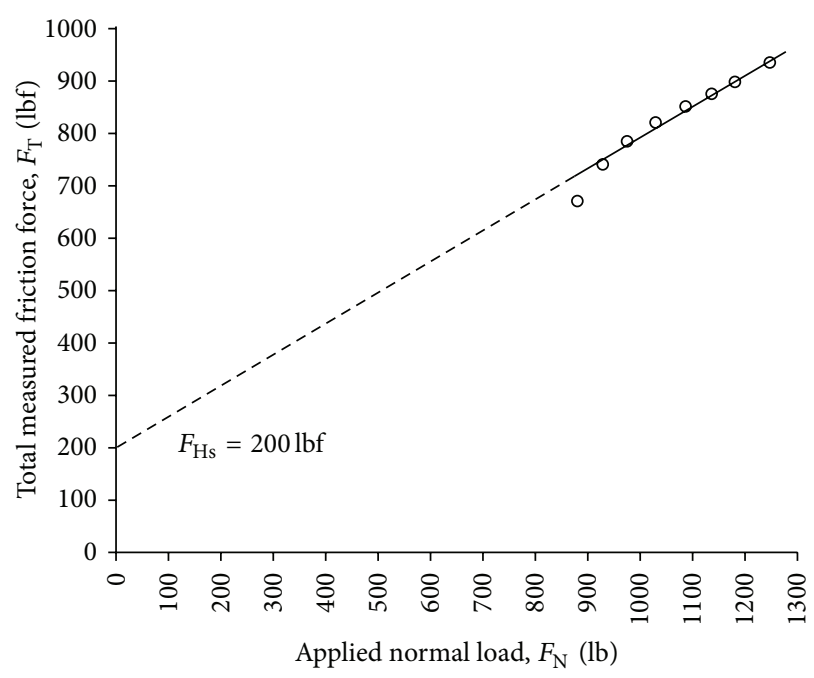

Figure 16: Dry Tyrone Boulevard test results.

pavement in the area of testing are readily apparent. Figure 16 presents the dry Tyrone Boulevard test results.

It is seen that seven of the eight $F_{\mathrm{T}}$ values, when connected by a straight-line and extrapolated to the $y$-axis, indicate generation of the microhysteretic friction force $F_{\mathrm{Hs}}$, having a magnitude of about $200 \mathrm{lbf}$. As with the dry asphalt testing, however, an outlier is present, in this case at the $883 \mathrm{lb}$ load. The continuous pavement temperature for the $883 \mathrm{lb}$ testing was $116^{\circ} \mathrm{F}$, while the pavement temperature during testing at the other loads averaged $74^{\circ} \mathrm{F}$. Puffs of smoke emanating from the tire/pavement contact patch were also observed during the dry concrete testing. These conditions are consistent with greater softening of the tire and a reduced $F_{\mathrm{T}}$ value at the $883 \mathrm{lb}$ load, as reported. A $F_{\mathrm{Hs}}$ value $200 \mathrm{lbf}$ was measured. Table 4 presents the applied loads and the associated $F_{\mathrm{T}}$ values.

5.4. Wet Concrete Pavement Testing. Wet testing of concrete using the ICC tester, always operated by the same experienced engineer, began on Tyrone Boulevard in St. Petersburg, Florida, on March 18, 2013, and was completed on March 22, 2013, both during daylight hours. Traffic on Tyrone Boulevard 
TABLE 5: Individual weights selected for use in controlling the dynamic load $\left(F_{\mathrm{N}}\right)$ applied to test tire during lockups and measured $F_{\mathrm{T}}$ values wet concrete pavement testing.

\begin{tabular}{cccc}
\hline$\#$ & $F_{\mathrm{N}}$ normal load & Increase in load, $\%$ & $F_{\mathrm{T}} \mathrm{lbf}$ \\
\hline 1 & $883 \mathrm{lb}$ & - & 314 \\
2 & $930 \mathrm{lb}$ & 5.3 & 322 \\
3 & $984 \mathrm{lb}$ & 11.4 & 339 \\
4 & $1034 \mathrm{lb}$ & 17.1 & 352 \\
5 & $1084 \mathrm{lb}$ & 22.8 & 351 \\
6 & $1132 \mathrm{lb}$ & 28.2 & 363 \\
7 & $1188 \mathrm{lb}$ & 34.5 & 362 \\
8 & $1242 \mathrm{lb}$ & 40.7 & 426 \\
\hline
\end{tabular}

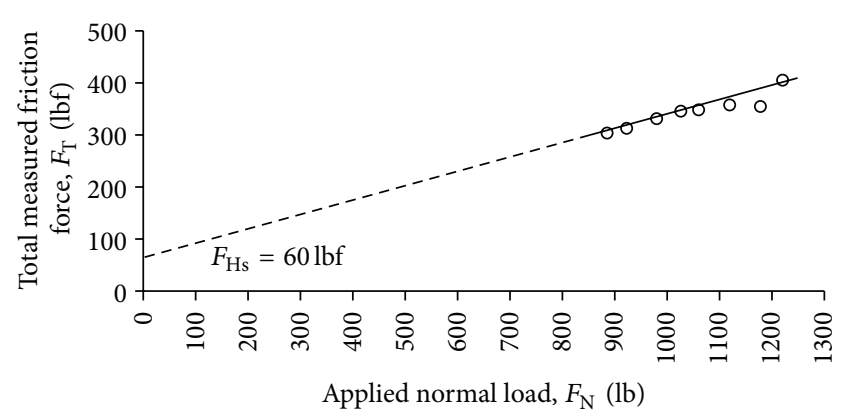

Figure 17: Wet Tyrone Boulevard test results.

was moderate; no significant interaction took place between it and the testing at $40 \pm 1 \mathrm{mph}$.

The new, run-in, full-scale ASTM E501-08 ribbed tire mounted on the left side of the tester with the standard 24 \pm 0.5 psi inflation pressure was used.

Five lockup cycles of three individual tests were done for each of the eight applied loads. The results were averaged to obtain a mean value for $F_{\mathrm{T}}$, generated by each load. These test data were always obtained by the same engineer in the same lateral roadway position in the same operating lane, recorded for $1 \mathrm{sec}$. Figure 17 presents the wet Tyrone Boulevard results. Table 5 presents the normal tire loads and their associated $F_{\mathrm{T}}$ values.

It is seen that seven of the $F_{\mathrm{T}}$ values fall on or in contact with the straight-line which, when extrapolated, indicates generation of the microhysteretic friction force, $F_{\mathrm{Hs}}$, having a magnitude of about $60 \mathrm{lbf}$.

The $1188 \mathrm{lb}$ data point, however, could be considered an outlier. The ICC experience with their routine locked-wheel testing in wet conditions on different days likely provides the explanation for the discrepancy.

5.5. Summary of Test Results and Proposed Sliding Friction Index Values. Table 6 summarizes the loading-basedinterpretation results with $F_{\mathrm{Hs}}$ values for all four sets of the friction test data. Higher values of the microhysteretic force for the unpolished asphalt indicate superior microtexture characteristics at the time of testing compared to the polished concrete pavement.
TABLE 6: Summary of friction test results from the four tests reporting values of their associated sliding friction index.

\begin{tabular}{lcccc}
\hline \# & Pavement type & Test condition & $F_{\mathrm{Hs}}$, lbf & Sliding friction index \\
\hline 1 & Asphalt & Dry & 140 & 0.60 \\
2 & Asphalt & Wet & 220 & 0.60 \\
3 & Concrete & Dry & 200 & 0.58 \\
4 & Concrete & Wet & 60 & 0.58 \\
\hline
\end{tabular}

Using the loading-based approach, a "sliding friction index" (SFI) is proposed as an improved metric for slidingtire friction calculations resulting from variable $F_{\mathrm{N}}$ values, presented in Section 8.3.

5.6. Coefficient of Friction Values for All Four Locked-Wheel Tests. Table 7 presents the $f$ values for all four lockedwheel test results. These are reported here for comparison to the use of the tire-loading-based approach, which allows separate quantification of the $F_{\mathrm{Hs}}$ force. Each calculation used the mean value of the corresponding $F_{\mathrm{T}}$ measurement and unavoidably has an $F_{\mathrm{Hs}}$ force component.

\section{A Unified, Loading-Based Engineering Theory of Tire/Pavement Friction}

As discussed, Kummer proposed [1] a unified theory of sliding-tire/pavement friction in 1966, expressing the total friction force produced as the sum of its components. These included adhesion, $F_{\mathrm{A}}$, associated with the combined surface free energies of the paired materials. He considered that bulk deformation of the tire tread on rough pavements produces a macrohysteretic frictional contribution, $F_{\mathrm{Hb}}$. He also included tire wear, or cohesion loss, $F_{C}$. Kummer's purpose for proposing the theory was to "improve the frictional coupling between tires and wet road surfaces, particularly at high speeds."

Building on Kummer's approach, an expanded, unified, loading-based engineering theory of tire/pavement friction has been proposed [3, 8]. The theory incorporates the microhysteretic rubber friction force, the evidence for which has now been indicated by locked-wheel testing:

$$
F_{\mathrm{T}}=F_{\mathrm{A}}+F_{\mathrm{Hb}}+F_{\mathrm{C}}+F_{\mathrm{Hs}}
$$

where $F_{\mathrm{T}}$ is the total frictional sliding resistance of the tire on pavement surfaces, $F_{\mathrm{A}}$ is the adhesion force arising from the combined surface free energies of the paired materials, $F_{\mathrm{Hb}}$ is the bulk deformation of the tire tread, $F_{C}$ is the cohesion loss component from tire wear, and $F_{\mathrm{Hs}}$ is the contribution from the constant microhysteretic friction force.

It should be noted that Kummer [1] included the $F_{C}$ term for completeness but opined that its magnitude in particular short-term circumstances could be negligible. It should also be noted that $F_{\mathrm{A}}$ and $F_{\mathrm{Hb}}$ are not necessarily independent. Adhesion-assisted macrohysteresis can increase $F_{\mathrm{Hb}}$ force development in some circumstances by adhering tire rubber to rough pavement surfaces more closely [3]. 
TABLE 7: Calculated $f$ values for all locked-wheel tests.

\begin{tabular}{|c|c|}
\hline \multicolumn{2}{|c|}{ Dry Belcher Road asphalt } \\
\hline$F_{\mathrm{N}}$ values & $f$ values \\
\hline $883 \mathrm{lb}$ & 0.78 \\
\hline $930 \mathrm{lb}$ & 0.76 \\
\hline $984 \mathrm{lb}$ & 0.66 \\
\hline $1034 \mathrm{lb}$ & 0.58 \\
\hline $1084 \mathrm{lb}$ & 0.78 \\
\hline $1132 \mathrm{lb}$ & 0.78 \\
\hline $1188 \mathrm{lb}$ & 0.75 \\
\hline $1242 \mathrm{lb}$ & 0.74 \\
\hline \multicolumn{2}{|c|}{ Wet Belcher Road asphalt } \\
\hline $883 \mathrm{lb}$ & 0.45 \\
\hline $930 \mathrm{lb}$ & 0.41 \\
\hline $984 \mathrm{lb}$ & 0.41 \\
\hline $1034 \mathrm{lb}$ & 0.44 \\
\hline $1084 \mathrm{lb}$ & 0.41 \\
\hline $1132 \mathrm{lb}$ & 0.40 \\
\hline $1188 \mathrm{lb}$ & 0.36 \\
\hline $1242 \mathrm{lb}$ & 0.36 \\
\hline \multicolumn{2}{|c|}{ Dry Tyrone Boulevard concrete } \\
\hline $883 \mathrm{lb}$ & 0.75 \\
\hline $930 \mathrm{lb}$ & 0.80 \\
\hline $984 \mathrm{lb}$ & 0.80 \\
\hline $1034 \mathrm{lb}$ & 0.80 \\
\hline $1084 \mathrm{lb}$ & 0.78 \\
\hline $1132 \mathrm{lb}$ & 0.77 \\
\hline $1188 \mathrm{lb}$ & 0.76 \\
\hline $1242 \mathrm{lb}$ & 0.75 \\
\hline \multicolumn{2}{|c|}{ Wet Tyrone Boulevard concrete } \\
\hline $883 \mathrm{lb}$ & 0.34 \\
\hline $930 \mathrm{lb}$ & 0.35 \\
\hline $984 \mathrm{lb}$ & 0.34 \\
\hline $1034 \mathrm{lb}$ & 0.34 \\
\hline $1084 \mathrm{lb}$ & 0.32 \\
\hline $1132 \mathrm{lb}$ & 0.32 \\
\hline $1188 \mathrm{lb}$ & 0.31 \\
\hline $1242 \mathrm{lb}$ & 0.34 \\
\hline
\end{tabular}

\section{Practical Applications of the Loading-Based Approach}

7.1. Contributions to Vehicle Dynamics Analysis. As shown in Figure 1 and other plots presenting test results reported here as $F_{\mathrm{T}}$ versus $F_{\mathrm{N}}$, increasing the applied normal load increases the resulting tire/pavement friction force. As discussed in Section 3, use of the coefficient of friction and skid number can inadvertently result in misinterpreting developed friction-force assessments. This can be illustrated by considering a simple example in vehicle dynamics.
When a two-axle motor vehicle decelerates during straight-ahead braking on a horizontal pavement, dynamic load transfer from the rear axle to the front axle can occur. During this process, loads on the rear tires decrease while the front tires can experience increased loading. Because the $\mathrm{CoF}$ is not generally constant under varying load, a larger coefficient can therefore seemingly apply to the rear tires as the vehicle slows while a smaller friction ratio would apparently be associated with the front tires, opposite indications of actual friction-force generation.

Use of the loading-based approach can allow calculation of the actual $F_{\mathrm{TS}}$ forces generated at desired slip angles and $F_{\mathrm{N}}$ values of interest. When drivers make routine intersection turns or steering adjustments to follow roadway curvature, lateral friction forces are produced. Knowledge of such data would appear valuable to vehicle dynamists for use when quantifying the lateral sliding resistance needed to overcome inertial forces arising during such maneuvers, thereby keeping vehicles on the road.

7.2. Monitoring the Microtexture Depth Variation of Pavement Surfaces. It has been previously recognized that the study of tire traction should include pavement microtexture. Bond et al. conducted investigations regarding the importance of wet pavement microtexture, reported in 1974 [16]. They found that microroughness plays a significant role in tire traction in wet conditions. Their research encompassed seasonality issues and discovered that wet traction increased to a maximum in winter and fell to a minimum in summer. Examination of photomicrographs of in-service pavements revealed that pavement microroughness increased to a maximum in winter due to frost and other natural weathering effects on road aggregate during this period. It was also found that traffic polishing dominated during the summer, thereby removing the aggregate's microtexture to a considerable extent. These findings correlated well with the frequency of traffic incidents, fewer in winter and a greater number in summer.

Bond et al. [16] further determined that the wet traction indicated to be provided by the pavement microroughness was minimal unless the aggregates' topographical depth was greater than a critical value, on the order of $1.95 \times 10^{-4} \mathrm{in}$. Above this value, wet-roadway skid resistance increased rapidly.

Williams reviewed [17] the state-of-the-art of tire/ pavement traction in 1992, with a particular interest in a tire's roadholding ability in wet conditions. Recognizing the importance of an adequate pavement microtexture, he stated the following:

There is no substitute for the appropriate level of microtexture for aggregates in the new and traveled condition. The most desirable level of microtexture relates to its ability to remove the remaining thin film of water to create real areas of contact with the tread compound. Levels of microtexture below this minimum fail to generate high levels of wet friction. (p. 132) 
TABLE 8: Calculation of the sliding friction index (SFI) using data from TRB locked-wheel testing.

\begin{tabular}{lcccc}
\hline$F_{\mathrm{N}}$ value & $F_{\mathrm{T}}$ value & $F_{\mathrm{Hs}}$ value & Difference & Division BY $F_{\mathrm{N}}$ \\
\hline $800 \mathrm{lb}$ & $350 \mathrm{lbf}$ & $150 \mathrm{lbf}$ & $200 \mathrm{lbf}$ & $200 \mathrm{lb} / 800 \mathrm{lb}$ \\
$1000 \mathrm{lb}$ & $400 \mathrm{lbf}$ & $150 \mathrm{lbf}$ & $250 \mathrm{lbf}$ & $250 \mathrm{lb} / 1000 \mathrm{lb}$ \\
$1200 \mathrm{lb}$ & $450 \mathrm{lbf}$ & $150 \mathrm{lbf}$ & $300 \mathrm{lbf}$ & $300 \mathrm{lb} / 1200 \mathrm{lb}$ \\
\hline
\end{tabular}

Figures 13 and 17 present test results allowing quantification of the microhysteretic rubber friction force, $F_{\mathrm{Hs}}$, in wet conditions, obtained by routine use of a locked-wheel tester. The $F_{\mathrm{Hs}}$ measurements of unpolished Belcher Road (220 lbf) and polished Tyrone Boulevard (60 lbf) are consistent with the findings of Bond et al. [16] and Williams [17]. These results, which were obtained in a few days of testing, reveal significant differences in the magnitudes of the respective $F_{\mathrm{Hs}}$ forces. The ability of routine locked-wheel testing, the results of which were likely influenced, at least in part, by pavement microtexture characteristics, suggests that higher frictional resistance is measured on pavements with greater microtexture depth. An improved loading-based data interpretation was used to develop a "sliding friction index" discussed below in Section 7.5. Seasonal testing and testing on other road pavements with different microtexture characteristics should help to demonstrate broad applicability of the proposed friction index model. It would provide a reliable indication of the variation of friction index arising from varying $F_{\mathrm{N}}$.

7.3. A Lateral Friction Tester in Current Use. Investigation has revealed that there is at least one mobile side friction device in routine use-the fleet of SCRIM ${ }^{\circledR}$ testers operated by the Transportation Research Laboratory (TRL) in the UK. The Sideway-force Coefficient Routine Investigation Machine, or SCRIM, measures the lateral friction produced in controlled wet conditions by use of a freely rotating smooth rubber tire fixed at a slip angle of $20^{\circ}$ to the direction of travel of the testing vehicle. While not presently used in accordance with the tire-loading-based approach, plotting the reported data as shown in Figure 9 would reveal the true $F_{\mathrm{TS}}$ versus $F_{\mathrm{N}}$ relationship and quantify the value of $F_{\mathrm{Hs}}$.

Using the SCRIM data at the $20^{\circ}$ slip angle in this manner appears suitable for monitoring the microtexture depth variation of roadway pavement surfaces discussed in Section 7.2. In fact, the stated purpose of SCRIM testing is "to determine the need to treat the [test] site to restore skid resistance."

7.4. Alternative Approach to the Coefficient of Friction in the Geometric Design of Roads. Section 3 discussed and illustrated (Figures 1 and 6) how the use of the coefficient of friction and skid number can lead to inadvertent misassessments when analyzing locked-wheel test results. At present there is no accepted, verifiable, comprehensive, rational theory of rubber friction incorporating the $\mathrm{CoF}$ term, which itself is not a material property of elastomers. For safety reasons, application of the validated tire-loadingbased approach and the sliding friction index in appropriate transportation segments is recommended instead.
The coefficient of friction, designated as $f$, is widely used in equations presented in the Green Book [18], the basic American roadway geometric design manual. This manual, under continuing development over many decades and involving the participation of numerous skilled engineers and experienced designers, has made an enormous and lasting contribution to the practice of transportation safety and efficiency [18]. The practice, when involving $f$, however, does not consider contributions of the microhysteretic force $\left(F_{\mathrm{Hs}}\right)$ arising from sliding-tire contact with the pavement's microtexture.

7.5. Sliding Friction Index. By accepting the existence of the microhysteretic friction force $\left(F_{\mathrm{Hs}}\right)$ and accounting for it in the analysis of locked-wheel testing, it is possible to generate a rational number quantifying the variable frictional sliding resistance produced when different values of applied tire loads $\left(F_{\mathrm{N}}\right)$ are used in such testing.

The process involves subtraction of the constant $F_{\mathrm{Hs}}$ value from the total measured friction force $\left(F_{\mathrm{T}}\right)$ generated from each such applied load. This may be illustrated using the locked-wheel testing data published by the Transportation Research Board [4] in 1974 and shown in Figure 1, in which a $F_{\mathrm{Hs}}$ force of $150 \mathrm{lbf}$ was produced using three different applied loads of $800 \mathrm{lb}, 1000 \mathrm{lb}$, and $1200 \mathrm{lb}$. In this testing, the corresponding $F_{\mathrm{T}}$ values were $350 \mathrm{lbf}, 400 \mathrm{lbf}$, and $450 \mathrm{lbf}$, respectively. Table 8 presents the appropriate calculations. It is seen that subtraction of the $150 \mathrm{lbf} F_{\mathrm{Hs}}$ force from the three $F_{\mathrm{T}}$ values yields $200 \mathrm{lbf}, 250 \mathrm{lbf}$, and $300 \mathrm{lbf}$, respectively. Division of these resultants by their respective $F_{\mathrm{N}}$ quantities yields the dimensionless sliding friction index (SFI) value of 0.25 for all three loads. Figures 18, 19, 20, and 21 present SFI values for the present wet and dry locked-wheel test results. The outlier values were not included in these SFI calculations.

\section{Conclusions}

8.1. Role of Pavement Microtexture in Sliding Resistance. The importance of pavement microtexture was discussed in Section 7.2. It had been realized in 1974 [16] from tests on inservice roadways in which pavement microroughness plays a significant role in tire traction in wet conditions. These roads included those that were highly polished by summer driving and others that had experienced microroughness enhancement from winter frost. Photomicrographic studies revealed that the usefulness of pavement microtexture in wet conditions is minimal unless it exceeds about $1.95 \times 10^{-4}$ in. in depth. These findings correlated well with the frequency of traffic incidents, fewer in winter, and a greater number in summer. 


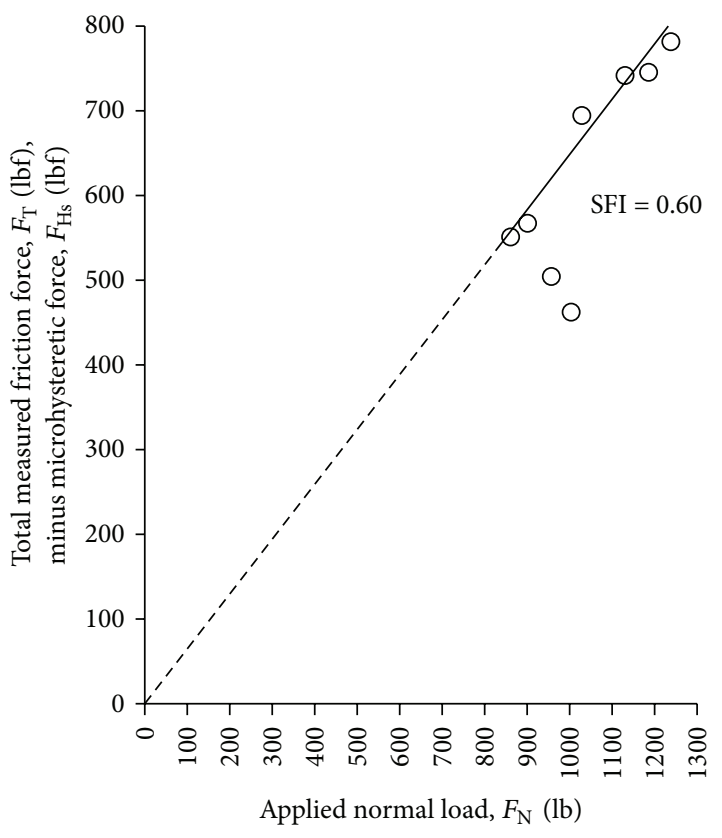

FIGURE 18: Dry Belcher Road test results showing the sliding friction index (SFI) value.

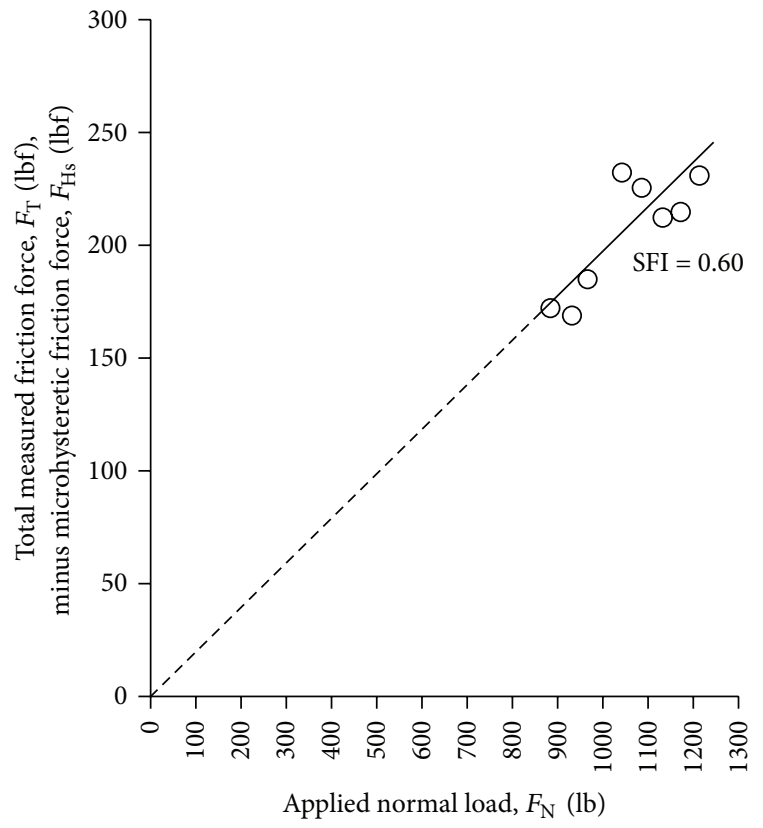

FIGURE 19: Wet Belcher Road test results showing the sliding friction index (SFI) value.

It was subsequently discovered that [17] an adequate depth of pavement microtexture plays a role in contributing to a tire's roadholding ability in wet conditions. The most desirable microtexture roughness is one that assists the tire in removing any surface water film present so as to create real areas of contact with the tread.

Figures 13 and 17 present wet test results obtained by routine use of a locked-wheel tester allowing quantification of

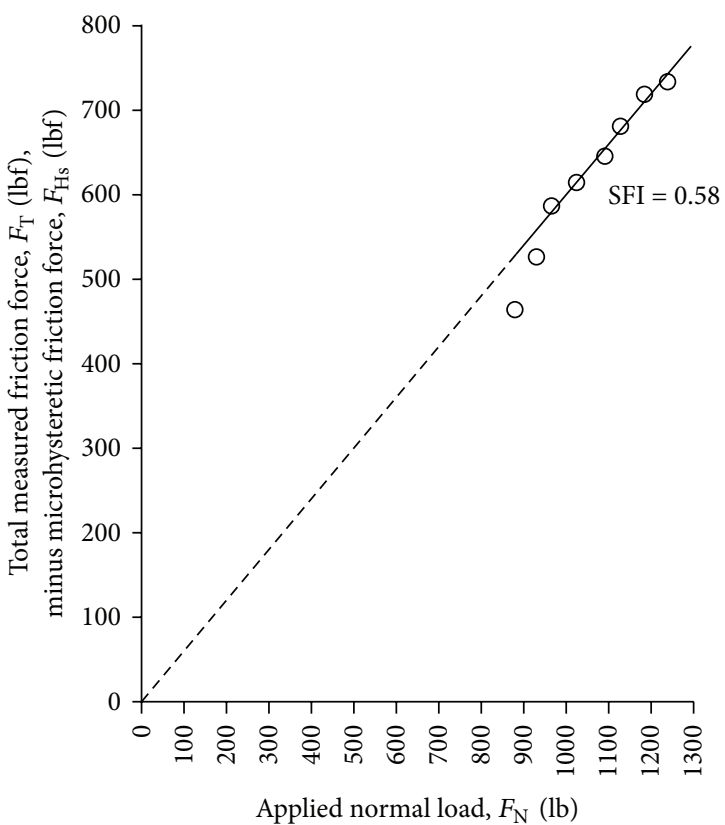

FIgure 20: Dry Tyrone Boulevard test results showing the sliding friction index (SFI) value.

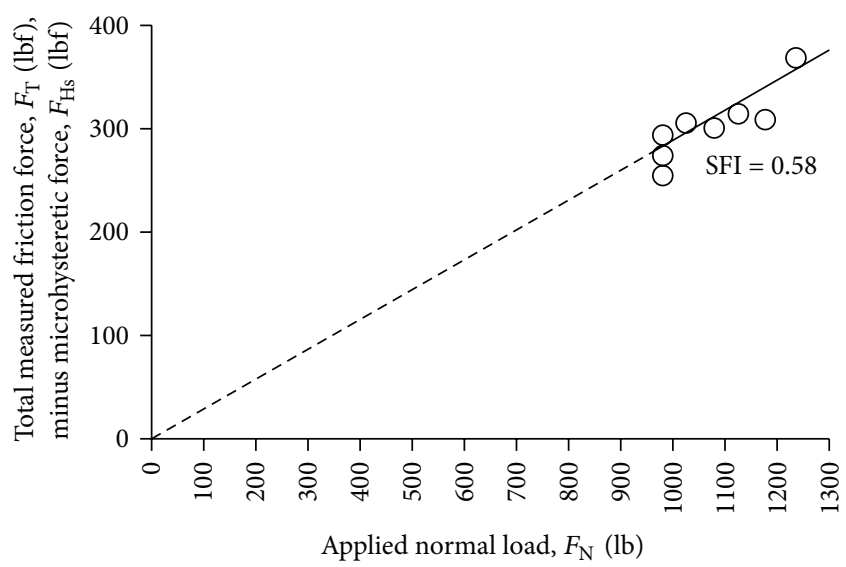

Figure 21: Wet Tyrone Boulevard test results showing the sliding friction index (SFI) value.

the microhysteretic rubber friction force, $F_{\mathrm{Hs}}$, as a metric for assessment of pavement microroughness and its component contribution to the total potentially available $F_{\mathrm{T}}$ force, along with the tire loading component.

The $F_{\mathrm{Hs}}$ measurements of unpolished Belcher Road (220 lbf) and polished Tyrone Boulevard (60 lbf) may be used as an example in this regard. The identical $F_{\mathrm{N}}$ loadings contributed a mean of 52 percent of the total Belcher Road $F_{\mathrm{T}}$ value, while the $F_{\mathrm{Hs}}$ component in the Tyrone Boulevard testing contributed a mean of 17 percent of total $F_{\mathrm{T}}$. Diamond grinding of concrete pavement is known to increase surface macrotexture. Locked-wheel ASTM testing to measure $F_{\mathrm{Hs}}$ would be required to determine if surface microtexture is also 
enhanced. Testing of asphalt pavement after milling would similarly need such testing for the same purpose.

In short, consider the following:

(i) Routine locked-wheel testing can be used to quantify the $F_{\mathrm{Hs}}$ value of a roadway segment.

(ii) $F_{\mathrm{Hs}}$ values can be used as a metric for assessing pavement microroughness.

(iii) Locked-wheel testing of diamond ground concrete pavement would be needed to determine if $F_{\mathrm{Hs}}$ increased.

(iv) Locked-wheel testing of asphalt pavement after milling would be required for the same purpose.

8.2. The Sliding Friction Index in Practical Application of Locked-Wheel Test Data. The importance of the sliding friction index (SFI) was discussed in Section 7.5. Measuring values of the $F_{\mathrm{Hs}}$ force can be readily accomplished through routine use of ASTM locked-wheel testing. Subtracting these values from the total measured friction force $\left(F_{\mathrm{T}}\right)$ quantifies the sliding resistance produced by application of the tire loads, $F_{\mathrm{N}}$. This technique permits determination of the dimensionless SFI, which accurately quantifies this second, distinct loading component of $F_{\mathrm{T}}$.

8.3. The Two-Pronged Approach Needed to Utilize the Total Sliding Resistance Force Measured in Standard ASTM LockedWheel Testing. Because the SFI value is tire-load-dependent and the $F_{\mathrm{Hs}}$ force is tire-load-independent, a two-pronged approach is needed for application of these two distinct sliding friction forces measured in standard ASTM lockedwheel testing. This may be readily accomplished by use of a simple force-combining equation:

$$
F_{\mathrm{F}}=F_{\mathrm{Hs}}+\mathrm{SFI} \times F_{\mathrm{N}},
$$

where $F_{\mathrm{F}}$ is the total frictional sliding resistance force measured by standard ASTM locked-wheel testing obtained through use of the loading-based approach to quantify $F_{\mathrm{Hs}}$ by extrapolation of the straight-line data plot to the $y$-axis, expressed as lbf, $F_{\mathrm{Hs}}$ is the value of the microhysteretic force measured by standard ASTM locked-wheel testing, expressed in $\mathrm{lbf}, \mathrm{SFI} \times F_{\mathrm{N}}$ is the the calculated SFI value obtained from the results of standard ASTM locked-wheel testing multiplied by the applied tire load of interest, expressed as lbf.

The following part exemplifies application of the forcecombining equation to the wet and dry asphalt and concrete test data at the $F_{\mathrm{N}}$ value of $1242 \mathrm{lb}$. It may be noted that the value of the wet Belcher Road $F_{\mathrm{Hs}}$ force was significantly larger $(220 \mathrm{lbf})$ than the value of the dry Belcher Road $F_{\mathrm{Hs}}$ force $(140 \mathrm{lbf})$. It may be recalled that generation of smoke was observed during the dry asphalt testing. The diminished $F_{\mathrm{Hs}}$ value appears consistent with this production of smoke. Perhaps the heat associated with the smoke also reduced the rigidity of the asphalt microtexture and/or led to diminished depth during the locked-wheel procedure.
Calculating Values for the Force-Combining Equation. Consider the following:

$$
\begin{aligned}
& F_{\mathrm{F}}=F_{\mathrm{Hs}}+\mathrm{SFI} \times F_{\mathrm{N}} \\
& \text { Dry Belcher Road } F_{\mathrm{F}}=140 \mathrm{lbf}+(0.60 \times 1242 \mathrm{lb}) \\
& \quad=745 \mathrm{lbf}+140 \mathrm{lbf}=885 \mathrm{lbf} \\
& \text { Wet Belcher Road } F_{\mathrm{F}}=220 \mathrm{lbf}+(0.60 \times 1242 \mathrm{lb}) \\
& \quad=745 \mathrm{lbf}+220 \mathrm{lbf}=965 \mathrm{lbf} \\
& \text { Dry Tyrone Boulevard } F_{\mathrm{F}}=200 \mathrm{lbf}+(0.58 \times 1242) \\
& \quad=720 \mathrm{lbf}+200 \mathrm{lbf}=920 \mathrm{lbf}
\end{aligned}
$$

Wet Tyrone Boulevard $F_{\mathrm{F}}=60 \mathrm{lbf}+(0.58 \times 1242)$

$$
=720 \mathrm{lbf}+60 \mathrm{lbf}=780 \mathrm{lbf} \text {. }
$$

8.4. Use of the Force-Combining Equation to Predict Skid Resistance and Braking Distance. Development of a testing data base comprising typical asphalt and concrete $F_{\mathrm{Hs}}$ and SFI values obtained by standard ASTM locked-wheel testing and analyzed by use of the force-combining equation in combination with stopping-distance testing will be needed to allow reliable prediction of skid resistance and braking distance.

In short, consider the following:

(i) Routine use of locked-wheel testing can measure the $F_{\mathrm{Hs}}$ values in pavement sections of interest.

(ii) These $F_{\mathrm{Hs}}$ values can be used to determine the rational, dimensionless SFI quantifying the sliding resistance attributable to tire loading.

(iii) Use of the loading-based approach for analysis of ASTM locked-wheel testing data permits measurement of the $F_{\mathrm{Hs}}$ force attributable to pavement microroughness, pavement surface free energy, and surface free energy of the sliding-tire tread.

8.5. Implementation Statement. Considering the evidence developed from the analysis of testing results involving data from both wet and dry asphalt and concrete pavements, together with the supporting matter discussed above, it is recommended that use of the skid number and coefficient of friction be reconsidered.

\section{Needed Research}

As shown in Figure 2 by the straight-line plot, when the $F_{\mathrm{Hs}}$ force is subtracted from $F_{\mathrm{T}}$, the associated $\mathrm{CoF}$ values are directly proportional to applied load in the commonly used locked-wheel $F_{\mathrm{N}}$ range. As shown by the straight-line plots in Figures 18, 19, 20, and 21-when the outlier points are ignored-the sliding friction index values are also directly proportional to applied load. Further research is needed in order to understand the underlying mechanism giving rise to this directly proportional characteristic. Such knowledge may 
prove valuable in practical application of the sliding friction index.

Archard $[19,20]$ has scientifically investigated the direct proportionality issue using macroscopically smooth materials sliding on macroscopically smooth surfaces. When using this approach only $F_{\mathrm{A}}$ friction forces are generated. Archard investigated pairings of smooth brass and pairings of smooth, nonelastomeric plastic, poly(methyl-methacrylate), or PMMA, all in the elastic loading range. He found that, as $F_{\mathrm{N}}$ increases, new real areas of contact between the paired surfaces can be established. He theorized that the additional friction forces generated would be directly proportional to the increased load if the primary result of such loading is to create new real areas of contact. Persson recently reexamined [21] Archard's theory and concurred with it.

\section{Disclosure}

The study was a part of a USDOT funded National Center for Intermodal Transportation for Economic Competitiveness (NCITEC) project on global supply chain management. The contents of this paper reflect the views of the author who is responsible for the facts, findings, and data presented herein. The contents do not represent the views of the agencies cited in this document. The author received remuneration for his consulting involvement.

\section{Competing Interests}

The authors declare that they have no competing interests.

\section{References}

[1] H. W. Kummer, "Unified theory of rubber and tire friction," Engineering Research Bulletin B-94, The Pennsylvania State University, 1966.

[2] P. Haney, The Racing \& High Performance Tire, SAE International, 2003.

[3] R. H. Smith, Analyzing Friction in the Design of Rubber Products and Their Paired Surfaces, CRC Press, Boca Raton, Fla, USA, 2008.

[4] W. E. Meyer, R. R. Hegmon, and T. D. Gillespie, "Locked-wheel pavement skid tester correlation and calibration techniques," Tech. Rep. 151, Transportation Research Board, National Cooperative Highway Research Program, National Research Council, Washington, DC, USA, 1974.

[5] B. N. J. Persson, "On the theory of rubber friction," Surface Science, vol. 401, no. 3, pp. 445-454, 1998.

[6] P. M. Pfalzner, "On the friction of various synthetic and natural rubbers on ice," Canadian Journal of Research, vol. 28, no. 12, pp. 468-489, 1950.

[7] K. Mori, S. Kaneda, K. Kanae, H. Hirahara, Y. Oishi, and A. Iwabuchi, "Influence on friction force of adhesion force between vulcanizates and sliders," Rubber Chemistry and Technology, vol. 67, no. 5, pp. 797-805, 1994.

[8] R. H. Smith and T. W. Neubert, "Calculating tire/pavement friction forces," International Journal of Pavements, vol. 10, no. 1-3, pp. 2-14, 2011.

[9] T. J. Yager, S. M. Stubbs, and P. M. Davis, "Aircraft radial-belted tire evaluation," in Emerging Technologies in Aircraft Landing
Gear, J. A. Tanner, P. C. Ulrich, J. P. Medzorian, and D. L. Morris, Eds., Paper 901931, pp. 243-250, SAE International, Warrendale, $\mathrm{Pa}, \mathrm{USA}, 1997$.

[10] ASTM International, "Standard specifications for special purpose, smooth-tread tire, operated on fixed braking slip continuous friction measuring equipment," ASTM E1551-08, ASTM International, West Conshohocken, Pa, USA, 2008.

[11] T. J. W. Leland, T. J. Yager, and U. T. Joyner, "Effects of pavement texture on wet-runway braking performance," NASA Publication TN D4323, NASA, 1968.

[12] ASTM International, "Standard specifications for standard rib tire for pavement skid-resistance tests," ASTM E501-08, ASTM International, 2015.

[13] ASTM International, "Standard test method for skid resistance of paved surfaces using a full-scale tire," ASTM E274/E274M-11, ASTM International, West Conshohocken, Pa, USA, 2011.

[14] USA Today, "Interview with aircraft Captain Cox," April 2013.

[15] Minnesota Department of Transportation, Minnesota's AstroTurf Drag Technique Texturing Concrete Pavements, Minnesota Department of Transportation, Saint Paul, Minn, USA, 2005, http://www.dot.state.mn.us/materials/researchastroturf.html.

[16] R. Bond, G. Lees, and A. R. Williams, "An approach towards the understanding of the tyre," in The Physics of Tire Traction-Theory and Experiment, D. F. Hays and A. L. Browne, Eds., chapter 4, Plenum Press, 1974.

[17] A. R. Williams, "A review of tire traction," in Vehicle, Tire, Pavement Interface, J. J. Henry and J. C. Wambold, Eds., p. 132, ASTM, West Conshohocken, Pa, USA, 1992.

[18] American Association of State Highway and Transportation Officials, A Policy on Geometric Design of Highways and Streets, American Association of State Highway and Transportation Officials, 6th edition, 2011.

[19] J. F. Archard, "Elastic deformation and the contact of surfaces," Nature, vol. 172, pp. 918-919, 1953.

[20] J. F. Archard, "Elastic deformation and the laws of friction," Proceedings of the Royal Society A, vol. 243, no. 1233, pp. 190205, 1957.

[21] B. Persson, Sliding Friction: Physical Principles and Applications, Springer, Berlin, Germany, 2000. 


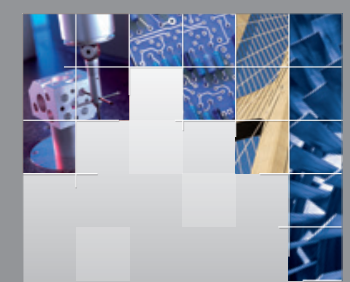

\section{Enfincering}
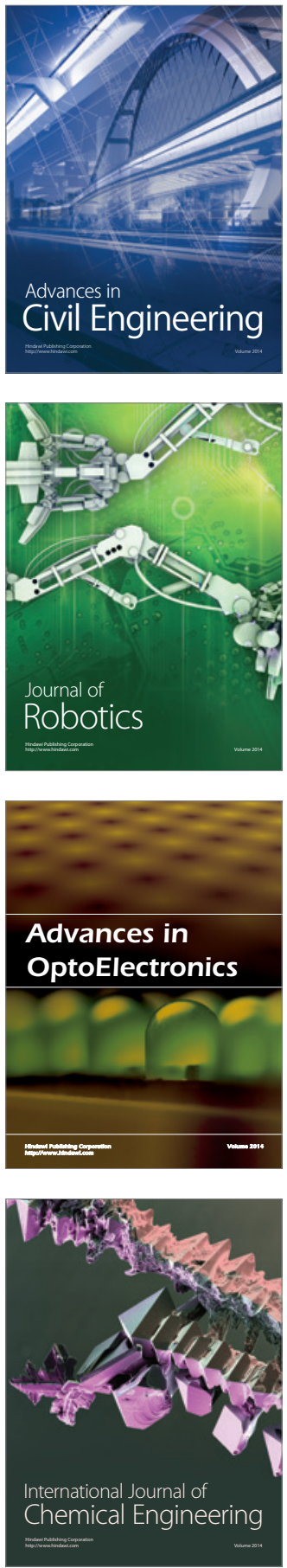

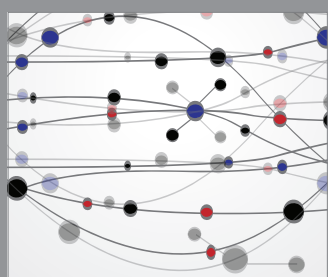

The Scientific World Journal

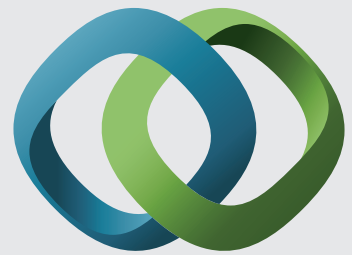

\section{Hindawi}

Submit your manuscripts at

http://www.hindawi.com
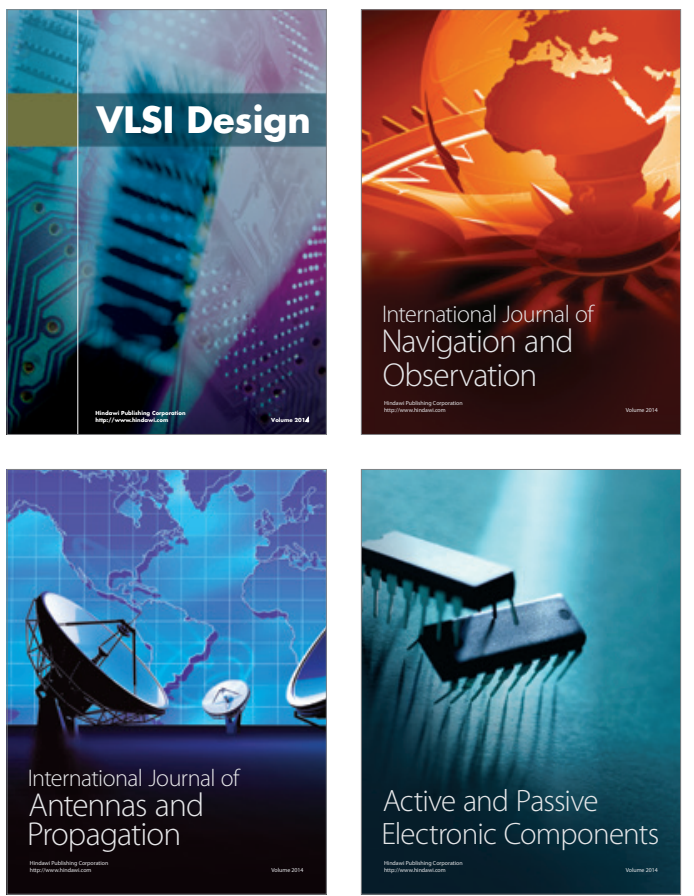
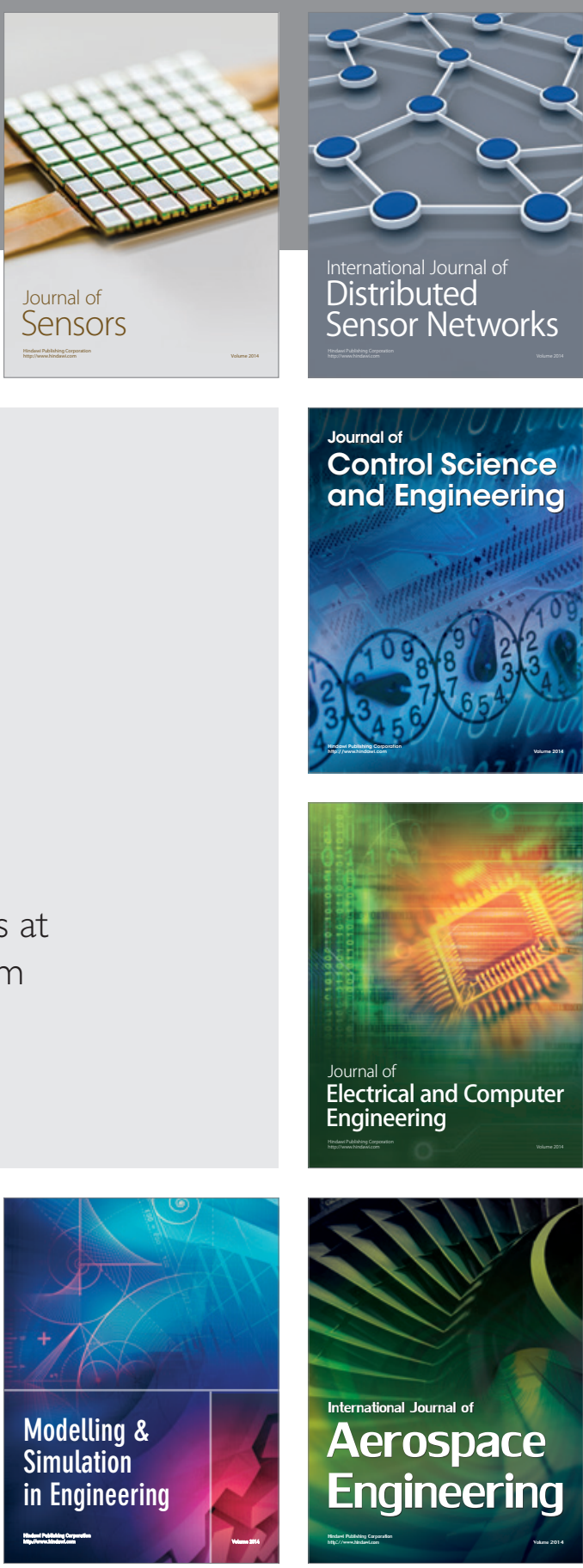

International Journal of

Distributed

Sensor Networks

Journal of

Control Science

and Engineering
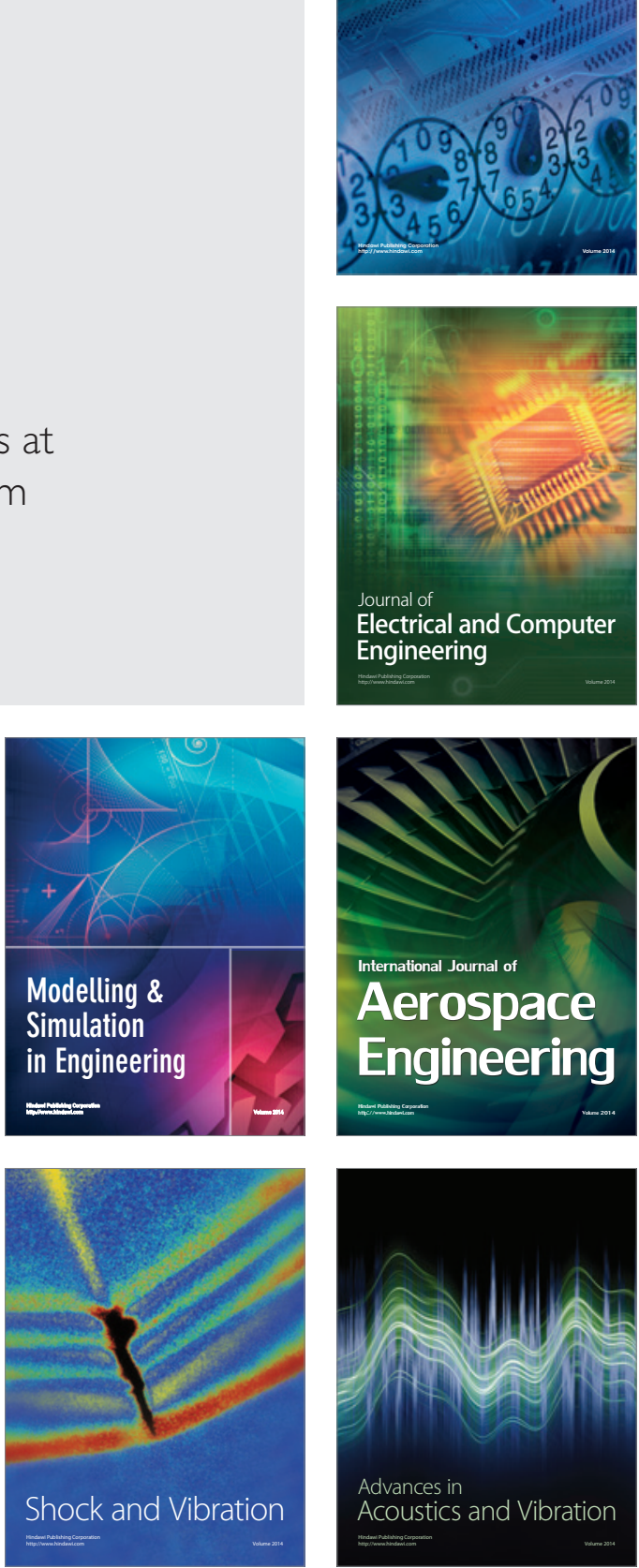